\title{
Política exterior chilena y MERCOSUR: Hacia una seguridad subregional con medidas de confianza mutua (2000-2010)
}

\author{
Jorge Vera Castillo.
}

En este articulo, el autor propone el establecimiento de nuevas formas de vinculación entre Chile y el MERCOSUR, considerando no solamente los aspectos comerciales y económicos, sino también, la cooperación política que incorpore la seguridad y la defensa.

La buisqueda de una seguridad subregional vecinal y vecinal viable, sustentada en sólidas Medidas de Confianza Mutua, hará posible mantener la integridad nacional en el marco de un regionalismo abierto.

\section{Presentación}

El tema que desarrollo en este trabajo, se resume adecuadamente en sus contenidos, en el título precedente, como propuesta de futuro, que se inicia hoy.

La política exterior chilena, en el próximo decenio, debiera proponer distintivas y nuevas vinculaciones con el MERCOSUR, ya fuere en la tradicional esfera de las relaciones bilaterales con cada uno de sus cuatro actuales estados partes (Argentina, Brasil, Paraguay y Uruguay), o bien, en tanto cuanto Chile cambie su actual condición de país asociado al MERCOSUR, pasando a ser estado parte (o país miembro) del MERCOSUR en un próximo futuro, dentro de los años venideros. Además estas relaciones exteriores del país deberán considerar el vínculo bilateral con Bolivia, dado que también es actualmente país asociado al MERCOSUR. Mas, en esta investigación y propuesta, nuestros énfasis estarán orientados a las relaciones de Chile con el MERCOSUR, propiamente tal, como proyecto e institucionalidad de integración subregional en América del Sur, que 
"trasciende los aspectos exclusivamente comerciales y económicos". ${ }^{1}$

El desarrollo que presento en este material de discusión estará referido y más restringido, a un nuevo aspecto de las vinculaciones de Chile con el MERCOSUR -aún considerando necesariamente el período de análisis desde 1991, en sus antecedentes principales-, cual es la esfera de seguridad y defensa, como proyección y manifestación inherentes de la futura política exterior chilena.

Para ello, será necesario, dentro de sus prioridades, postular una nueva mirada de dicha política exterior hacia el MERCOSUR, en los años 20002010, a partir de una emergente realidad que se orienta a la consulta y concertación política entre los Estados partes del MERCOSUR, Bolivia y Chile, y que se intenta concretar a través de la cooperación política, que es "entendida como aquella cooperación referida a todos los campos que no formen parte de la agenda económica y comercial de la integración."2 Lo anterior se encontrará, a continuación, en la Sección I de este documento.

La esfera de la seguridad y la defensa, en el marco de nuestro tema, nos plantea adentrarnos en las nuevas conceptualizaciones de la seguridad regional -que comienzan a manifestarse e incubarse desde los inicios de los años noventa en las Américas-, como contexto y contenido esencial a consignar en la Sección II. Los antecedentes y las propuestas de Medidas de Confianza Mutua (MCM), para ser recomendadas en el ámbito interamericano -en formas, instancias y prácticas concretas-, las consideramos, detalladamente, en la Sección IIII.

Posteriormente, en una Sección IV, abordaremos las nuevas vinculaciones de Chile con el MERCOSUR, especialmente simbolizadas a partir de 1995 , pero que en lo referido a los contenidos, interés y enfoque de nuestro tema, se contextualizan y se expresan ya más significativamente desde 1997, y debieran seguir expresándose en los próximos años, desde el inicio del nuevo siglo XXI.

El avance del desarrollo de este trabajo nos demandará, en consecuencia, tener una visualización -como postulación principal político-estratégica-

${ }^{1}$ Véase en texto íntegro del comunicado conjunto de los presidentes. VII Reunion del consejo del mercado común. Ouro Preto, República Federativa del Brasil, 17 de diciembre de 1994: en Integración latinoamericana, año 19, n 206, Intal, Buenos Aires, diciembre 1994, punto 7., p. 65.

2 Véase en texto íntegro de la Declaracion presidencial sobre la consulta y concertacion politica. Asunción, 17 de junio de 1997: en Boletín oficial del MERCOSUR, año i, n 3/97, Montevideo, diciembre 1997, punto 1., p. 119. 
que se orientará hacia una seguridad subregional y vecinal viable, como desafío de edificación de una arquitectura cimentada en sólidos fundamentos, para el conjunto del MERCOSUR (sus estados partes y sus países asociados) y para el desarrollo y preservación de nuestros intereses e identidad nacionales, en el contexto de un regionalismo abierto y de una integración subregional multifacética, y como contribución y responsabilidad nacional e interestatal frente a la paz y seguridad internacionales. De esto nos ocupamos en la Sección V.

El conjunto de los materiales analizados, desarrollados e investigados en los contenidos de las Secciones anteriores, nos permitirán precisar, por tanto, algunas sugerencias de política para un nuevo Gobierno, a partir del mes de marzo del 2000, para la Política exterior Chilena y el MERCOSUR, lo cual de expresará en la Sección VI. La investigación académica especializada debe ser capaz de hacer una contribución comprensible, correspondiente y efectiva para la elaboración y formulación de una política en una esfera específica -la seguridad y la defensa en sus alcances y seguimientos internacionales- $y$, por cierto, para su puesta en práctica, como parte esencial del conjunto de las políticas de estado del país, a lo menos, durante el próximo decenio, en su inserción internacional.

Este material de discusión concluye con el sentido más profundo de sus contenidos, en las relaciones de Chile con y/o en el MERCOSUR y en sus relaciones bilaterales vecinales, en el contexto regional de América del Sur y en el ámbito subregional del llamado Cono Sur -como objetivo específico-, a través de una afirmación central: se trata de estar promoviendo la seguridad, demostrando confianza en las relaciones interestatales e intergubernamentales, a través de la voluntad política de todos los distintos actores institucionales y representantes oficiales de los gobiernos. Esto debiera complementarse siempre con informaciones oportunas y objetivas; un rol idóneo de los medios de comunicación social, y, unas percepciones educacionales, históricas y humanas adecuadas de nuestras opiniones públicas, que se vayan traduciendo en nuevos y verdaderos conocimientos y sentimientos hacia la integración por parte de nuestros pueblos.

Por último, se complementa este esfuerzo con dos anexos, que son parte cardinal de esta pesquisa. Las correspondientes notas bibliográficas, resultantes de la investigación, y la bibliografía utilizada -que se ordena según Artículos, Documentos, Libros, Monografías y Noticiario-, se incluyen en las páginas finales. 


\section{Política exterior chilena en la perspectiva del período 2000-2010: Una mirada hacia el MERCOSUR}

La política exterior chilena, durante el primer decenio del próximo siglo XXI, tendrá nuevos desafíos, oportunidades, perspectivas y potencialidades. Por cierto, esto no será indiferente al conjunto del desarrollo y la evolución política del país; ni podría plantearse en forma totalmente aislada, autónoma, diferente o distante, marchando por sus propios rumbos o, incluso, según las egocéntricas decisiones personales de un Ministro de Relaciones Exteriores, como ejecutor de las atribuciones especiales constitucionales del Presidente de la República, en cuanto a la conducción en esta esfera específica de la política gubernamental del Estado.

Para Chile, como país pequeño en población y producto nacional; alejado geográficamente de los grandes centros mundiales, y, dependiente y vulnerable en su inserción en la economía capitalista mundial -entre otras características y factores determinantes, identificatorios, limitantes y orientadores-, lo anterior es extraordinariamente válido, vigente y siempre necesario a ser tenido en cuenta.

Una adecuada síntesis de aquello, se encuentra en un aserto que escribiera hace ya poco más de un siglo un autor español. El postuló que: "el punto de partida de la política exterior de un país es la política nacional, puesto que de ésta depende el rumbo que se ha de imprimir a aquella; y asimismo el punto de partida de la política interior es la idea que se tiene del papel que la nación ha de representar en la política extranjera". ${ }^{3}$

Asimismo, otro elemento significativo, de carácter general, que toda elaboración, formulación y puesta en práctica de Política exterior debiera considerar es la actual situación y configuración de las relaciones internacionales, que han dado paso a lo que se conoce-sin mayor definición y/o precisión- como "globalización" o "proceso de globalización", siendo así "un concepto imperfecto"."

Si bien lo anterior no es enteramente nuevo, sí se trata de una nueva de-

\footnotetext{
3 Véase Gavinet, Angel. Idearium español, (escrito en octubre de 1896), Aguilar s.a. de Ediciones, Madrid, 1964 , pp. 78 y 79 .

4 Véase en Panorama de la insercion internacional de America Latina y el Caribe, edición 1996, Comisión económica para América Latina y el Caribe - Cepal, Santiago, lc/g.1941, 2 de diciembre de 1996, primera parte, capítulo i. a., pp. $19 \cdot 26$.
} 
nominación de una realidad cambiante, en forma vertiginosa en algunos aspectos. A la ya conocida afirmación de la existencia de una "interdependencia" creciente en el mundo, desde mediados de este siglo XX (que ya se aproxima a su término), se ha agregado ahora el nuevo fenómeno-denominación señalado. Baste recordar, como confirmación de lo precedente, que ya en 1950, un pensador francés, en su obra El Personalismo, fue visionario al escribir que: "Sin embargo, el mundo se internacionaliza de hecho cada vez más. No hay ya naciones independientes en el viejo sentido de la palabra." 5

Así, para toda la política exterior chilena en la perspectiva del período 2000-2010, las dos consideraciones-marco indicadas son cardinales e inmanentes. $\mathrm{Y}$ el establecimiento de prioridades en esa política no podrá ser ajeno a lo anterior.

Por otra parte, si bien es cierto que la región latinoamericana aparece lejana y no caracterizada por la actual problemática de los conflictos regionales activos, declarados y reconocidos, que sí se manifiestan en el escenario europeo, eurasiático y africano -bajo la forma de conflictos fronterizos, disputas étnicas, luchas autonómicas e independentistas, entre otras manifestaciones-, no es menos cierto que los legítimos intereses nacionales de quienes siguen siendo los principales actores políticos internacionales, como lo son los estados nacionales, siguen vigentes y, a veces, entran en colisión o conflicto, aún en el ámbito de los acuerdos y proyectos de integración entre sus países miembros o estados partes.

Lo precedente también es válido en el caso del MERCOSUR y, por cierto, para las relaciones de Chile con dicho esquema de integración, esencial e inicialmente comercial y económico.

De allí que el paso y la voluntad política de establecer como prioridad de la Política exterior Chilena, para el período 2000-2010, la perspectiva de sus relaciones con el MERCOSUR, es una apuesta de futuro de suma trascendencia y de la mayor responsabilidad internacional estatal y societal, para el conjunto del país y los conductores de su próximo nuevo Gobierno.

Debemos tener presente, por una parte, que el MERCOSUR es un proceso de integración relativamente reciente, desde el punto de vista

\footnotetext{
5 Vêase Mounier, Emmanuel. El personalismo, (ediciōn orìginal de 1950), Editorial Universitaria de Buenos Aires - Eudeba, quinta edición, febrero de 1968, p. 67.
} 
histórico, que se formaliza en su inicio el 26 de marzo de 1991, al suscribirse el Tratado de Asunción entre Argentina, Brasil, Paraguay y Uruguay ${ }^{6}, \mathrm{y}$ por otra, que Chile comienza a enfatizar sus vinculaciones y relacionamiento externo hacia el MERCOSUR, en forma diversificada e intensiva, progresivamente, desde hace sólo un corto período - desde 1994 -. Esta gradualidad de la aproximación chilena se va dando desde las demostraciones y manifestaciones de país interesado en dichos vínculos, con posterioridad a 1992; pasando a participar en calidad de país observador, desde el 5 de agosto de 1994 7; hasta llegar a su actual condición de país asociado, vigente desde el 17 de diciembre de $1997^{\circ}$.

Ciertamente, la voluntad política del gobierno del Presidente Eduardo Frei Ruiz-Tagle, se ha ido concretando en forma coherente con las intenciones manifestadas durante su campaña presidencial, desde 1993, y, posteriormente, desde 1994, de manera más intensiva, integracionista y, cualitativamente, a través de formulaciones más específicas y multifacéticas, en las relaciones y vinculaciones con el MERCOSUR y' sus Estados partes, como uno de los aspectos cada vez más importante de la política exterior chilena. En 1993, se sostenía que: "Chile no se plantea, por el momento, el ingreso al Mercosur; pero sí una vinculación inteligente y cuidadosa, capaz de ampararlos significativos flujos de comercio e inversiones en un esquema estable y no discriminatorio. Esa asociación especial, unida a los acuerdos con México, Venezuela, Bolivia y Colombia, deben convertir a Chile en un eje importante en la integración de América Latina." 9

La mirada hacia el MERCOSUR, hasta entonces, se reducía a los aspectos comerciales y económicos de dicho proceso de integración, desde la óptica de la aproximación de Chile a él, como parte de la integración latinoamericana. Esto era coherente con el propio desarrollo progresivo del

\footnotetext{
6 Véase tratado para la Constitucion de un Mercado Común entre la Republica Argentina, la Republica Federativa del Brasil, la Republica del Paraguay y la Republica Oriental del Uruguay. Tratado de Asuncion, suscrito en Asunción, República del Paraguay, el 26 de marzo de 1991: en Integracion Latinoamericana, año 16, $n^{\circ} 167$, intal, Buenos Aires, mayo 1991, pp. 111-113, y, anexos, pp. 113-117.

7 Véase declaracion de los presidentes del MERCOSUR y de la Republica de Chile. Buenos Aires, 5 de agosto de 1994: en Integracion Latinoamericana, año 19, $n^{\circ} 203$, Intal, Buenos aires, agosto-septiembre de 1994 , pp. 94 y 95.

${ }^{B}$ Véase participacion de Chile en reuniones del MERCOSUR. mercosur/cmc/dec. $\pi^{\circ} 12 / 97$, xiii cmc - Montevideo, 15/xii/ $/ 97$. con anterioridad, habia sido normada, a través del documento mercosur/cmc/dec. $n^{\circ} 14 / 96$, la participacion de terceros paises asociados en reuniones del mercosur, xi cmc - fortaleza, 17/12/g6.

- Véase en bases programaticas del segundo gobierno de la concertacion. un gobjerno para los nuevos tiempos. "Septimo compromiso: una politica exterior para los nuevos tiempos", Santiago, 1993, punto 16., p. 126.
} 
MERCOSUR, si bien ya desde 1992, sus estados partes habían comenzado a incorporar algunas breves consideraciones políticas, más allá de los "aspectos exclusivamente comerciales y económicos", y a desarrollar afirmación, presencia y relaciones externas.

En efecto, cabe consignar que en la II Reunión del Consejo del Mercado Común, celebrada los días 26 y 27 de junio de 1992, en Las Leñas, Argentina, el Comunicado de Las Leñas, en su punto 2. señala: "Los presidentes ratificaron que la plena vigencia de las instituciones democráticas es un supuesto indispensable para la existencia y el desarrollo del MERCOSUR." 10

Posteriormente, en el ya referido Comunicado Conjunto de los Presidentes, al término de la VII Reunión del Consejo del Mercado Común, realizada en Ouro Preto, Brasil, el 17 de diciembre de 1994, su Punto 4. indicó que ellos: "Reafirmaron la consolidación de los valores democráticos en el MERCOSUR, a los que consideran esenciales para la consecución del objetivo final del proceso de integración, es decir la conformación del Mercado Común." "I

Dados estos antecedentes y la naturaleza esencial e inicial del MERCOSUR, y como resultado de la búsqueda y voluntad política del Gobierno del Presidente Frei Ruiz-Tagle, se llegó a la expresión más relevante de este relacionamiento, en la esfera comercial y económica, representada por la suscripción del Acuerdo de Complementación Económica ChileMERCOSUR, en la Provincia de San Luis, Argentina, el 25 de junio de 1996, en forma paralela al desarrollo de la X Reunión del Consejo del Mercado Común. En la misma ocasión se suscribió un Protocolo sobre Integración Física. ${ }^{12}$

Se ha ido estableciendo, consolidando y ampliando una red bastante sólida de vinculaciones de Chile con el MERCOSUR -que retomaremos en detalle en la Sección IV de este artículo-, que servirán como guía para la acción venidera. ${ }^{13}$

\footnotetext{
so Véase en texto íntegro del Comunicado de las Leñas: en Integracion Latinoamericana, año $17, \mathrm{n}^{\circ} 180$, intal, buenos aires, julio de 1992, punto 2., p. 85 .

"Vêase op. cit., en nota bibllográfica 1/: véase punto 4., p. 65.

${ }^{12}$ Véase Acuerdo de complementacion economica Chile - MERCOSUR. suscrito en la provincia de San Luis, Repüblica Argentina, el 25 de junio de 1996: en Diplomacia, $n^{2}$ 69, Academia Diplomática, Santiago de Chile, marzo-junio 1996, pp. 88-99. para un balance preliminar de la implementación y marcha de este instrumento, véase Alejandro Marisio Cugat. "a dos años de la firma del acuerdo chile-mercosur", Diplomacia, $\mathrm{n}^{0}$ 77, Academia Diplomática, Santiago de Chile, octubre-diciembre 1998, pp. 83-88, texto integro del protocolo de integracion fisica, véase en: Memoria del Ministerio de Relaciones Exteriores, República de Chile, correspondiente al año 1996, pp. 983-985.

${ }^{13}$ Véase, anticipatoriamente, si se desea, anexo 1, en páginas 36 a 38.
} 
De allí que postular una mirada hacia el MERCOSUR, para la política exterior chilena en la perspectiva del período 2000-2010, es una opción política y político-estratégica de la mayor significación histórica para la inserción regional y subregional de nuestro país, en un contexto multifacético de nuevas esferas de relacionamiento bilateral y vecinal. Seguridad y defensa asoman ahora ineludibles.

Chile contribuirá a la edificación de un espacio económico ampliado, con unidad y concertación política democrática, en pos de una subregión segura, como resultado de un esquema, proceso y proyecto de integración innovador y' de nuevo tipo, para el bienestar de los pueblos del Cono Sur de América, en el siglo XXI.

\section{Reconceptualizaciones de la seguridad regional}

Para comenzar a visualizar la cooperación en la esfera de la seguridad y defensa entre los Estados partes del MERCOSUR, Bolivia y Chile, debemos tener adecuados fundamentos contextuales, informativos y resolutivos del proceso de reconceptualización de la seguridad regional, que se ha venido desarrollando, con especial énfasis, desde comienzos de esta década de los noventa.

Además, lo anterior es imprescindible conocerlo dado que Chile ha ido jugando, crecientemente, un rol internacional relevante en el señalado proceso, a partir del simbólico nexo con sus inicios formales, que se pueden considerar muy ligados a la Declaración (Compromiso) y Resoluciones del Vigésimo Primer Período Ordinario de Sesiones de la Asamblea General de la Organización de los Estados Americanos, realizado en Santiago, del 3 al 8 de junio de 1991.

Naturalmente, esta nueva situación en cuanto a la seguridad regional, desde el punto de vista de las fuerzas profundas de la historia, no puede considerarse alejada de importantes acontecimientos ocurridos en la región latinoamericana y el sistema interamericano, particularmente a partir de los enfrentamientos armados por la soberanía territorial de las Islas Malvinas ocurridos entre Argentina e Inglaterra, en 1982, por una parte, y por otra, el funcionamiento y viabilidad en esas circunstancias del Tratado Interamericano de Asistencia Recíproca (TIAR). ${ }^{14}$ 
Igualmente, América Latina y el Caribe no pueden analizarse, en profundidad, sin considerar adecuada y proporcionadamente las influencias y repercusiones que han tenido en la región los cambios ocurridos en la arena internacional, desde mediados de los años ochenta, junto con el posterior término de la llamada "guerra fría", período que se venía extendiendo desde comienzos de los años cincuenta de la segunda postguerra mundial. Y ello se manifestaba en el contexto de la configuración de unas relaciones internacionales contemporáneas que seguían siendo eurocéntricas y euroatlánticas ; pero que se expresaban, a nivel mundial, a través de la lucha, oposición y alternativa de dos sistemas sociales y económicos diferentes, con sus correspondientes alianzas militares y doctrinas estratégicas; junto con la existencia de países no alineados en vías de desarrollo.

Sin embargo, para los propósitos del desarrollo del tema de este material de discusión, intentaremos circunscribirnos a los hechos más significativos que van conformando la elaboración y formulación de reconceptualizaciones de la seguridad regional, especialmente desde 1991, y en consideración a los desarrollos atingentes a los estados partes y países asociados del MERCOSUR. Importantes esfuerzos, al respecto, se vienen intentando en distintas instancias interamericanas, regionales, subregionales, bilaterales y vecinales, las que debemos conocer para la implementación de una futura política exterior chilena.

La conocida conceptualización de la "seguridad colectiva" comenzó a ser cuestionada, tanto en los hechos como en los conceptos, desde hace casi ya dos décadas en la arena internacional. Sus fundamentos se encuentran en el marco de la Carta de las Naciones Unidas, de 1945, en los Capitulos VII y VIII. En el Artículo 51, se estipula que: "Ninguna disposición de esta Carta menoscabará el derecho inmanente de legítima defensa, individual o colectiva, en caso de ataque armado contra un Miembro de las Naciones Unidas, hasta tanto que el Consejo de Seguridad haya tomado las medidas necesarias para mantener la paz y la seguridad internacionales.". A la vez, el Artículo 52, Punto 1. contempla que: "Ninguna disposición de esta Carta se opone a la existencia de acuerdos u organismos regionales

\footnotetext{
${ }^{34}$ Véase texto íntegro del tratado interamericano de asistencia reciproca. suscrito en Río de Janeiro el 2 de septiembre de 1947 en la Conferencia Interamericana para el mantenimiento de la paz y la seguridad del continente: en serie sobre tratados 25, 0ea/ser.x/4 rev. 1, organizacion de los Estados Americanos, secretaria General, Washington, D.C., 1972, pp. 49-59.
} 
cuyo fin sea entender en los asuntos relativos al mantenimiento de la paz y la seguridad internacionales y susceptibles de acción regional, siempre que dichos acuerdos u organismos, y sus actividades, sean compatibles con los Propósitos y Principios de las Naciones Unidas."

En coherencia, el Tratado Interamericano de Asistencia Recíproca (TIAR), de 1947, se limita a recoger esta conceptualización en su Artículo 3, Puntol., que señala que: "Las Altas Partes Contratantes convienen en que un ataque armado por parte de cualquier Estado contra un Estado Americano, será considerado como un ataque contra todos los Estados Americanos, y en consecuencia, cada una de dichas Partes Contratantes se compromete a ayudar a hacer frente al ataque, en ejercicio del derecho inmanente de legítima defensa individual o colectiva que reconoce el Artículo 51 de la Carta de las Naciones Unidas." En el Punto 3., del mismo Artículo 3, se precisa que: "Lo estipulado en este artículo se aplicará en todos los casos de ataque armado que se efectúe dentro de la región descrita en el Artículo 4 o dentro del territorio de un Estado Americano." 15

Más adelante, el Artículo 6 del TIAR explícita que: "Si la inviolabilidad o la integridad del territorio o la soberanía o la independencia política de cualquier Estado Americano fueren afectadas por una agresión que no sea ataque armado, o por un conflicto extracontinental o intracontinental, o por cualquier otro hecho o situación que pueda poner en peligro la paz de América, el Organo de Consulta se reunirá inmediatamente, a fin de acordar las medidas que en caso de agresión se deben tomar en ayuda del agredido o en todo caso las que convenga tomar para la defensa común y para el mantenimiento de la paz y la seguridad del Continente." I6

Los enunciados textuales precedentes han sido cuestionados en los hechos por la propia práctica internacional, y en nuestra región han demostrado su fracaso.

Situados ya en los comienzos de estos años noventa, en el ámbito hemisférico territorial (división geográfica del mundo político y político-estratégico, a partir de la supuesta existencia de intereses comunes entre los Estados que se sitúan en determinado hemisferio, que no es compartida y es rechazada, analítica y metodológicamente, por el autor de este material de 
discusión) y regional latinoamericano (acepción y denominación más compartida y utilizada por el autor), la conceptualización de la seguridad hemisférica / regional comenzó a ser revisada con realismo, después de más de cuarenta años de intentos de aplicación de las concepciones sintetizadas en los párrafos de la página anterior, y con el propósito de buscar nuevos enfoques y formulaciones político-estratégicas, más viables.

Los intentos que revisaremos son recientes, ya que es posible constatar -a través de, por ejemplo, las Declaraciones de los Jefes de Estado del Grupo de los Ocho, como intento emergente de "concertación política" en la América del Sur, suscritas durante 1987-1989 ${ }^{17}$, que hasta fines de la década de los ochenta, las concepciones y mentalidades para abordar la temática de la seguridad hemisférica / regional seguían atadas a antiguos enfoques e impregnadas del ambiente de la llamada "guerra fría", impregnado de desconfianzas y prejuicios exacerbados.

Como ya señalábamos, es en Santiago de Chile, donde se pueden situar algunos de los puntos de partida de este proceso de reconceptualizaciones de la seguridad, a partir de 1991. En efecto, esto se manifiesta en el contexto del Compromiso de Santiago con la Democracia y la Renovación del Sistema Interamericano, aprobado en la tercera sesión plenaria del Vigésimo Primer Período Ordinario de Sesiones de la Asamblea General de la Organización de los Estados Americanos (OEA), celebrada el 4 de junio de 1991.

En dicho Compromiso de Santiago se consignó la "decisión de iniciar un proceso de reflexión conjunta sobre la seguridad hemisférica a la luz de las nuevas circunstancias mundiales y regionales, desde una perspectiva actualizada e integral de la seguridad y del desarme, incluido el tema de todas las formas de proliferación de armas e instrumentos de destrucción masiva, a fin de dedicar el mayor número de recursos al desarrollo económico y social de los Estados miembros; y formular un llamado a nivel mundial a otras organizaciones competentes, para que se unan a los esfuerzos de la OEA." 18

El resultado más concreto de dicha "decisión" fue la aprobación de dos valiosas Resoluciones durante el Vigésimo Primer Período Ordinario de

\footnotetext{
17 Véase en bibliografía, sección documentos: Compromiso de Acapulco... (1987), pp. 312*315; Declaracion de Uruguay (1988), pp. 323-325, y, Declaracion de Ica (1989), pp. 331-334.

${ }^{18}$ Véase en bibliografía, sección documentos: en Compromiso de Santiago..., 199a, p. 3.
} 
Sesiones: una, referida a la Cooperación para la Seguridad en el Hemisferio. Limitación de la Proliferación de los Instrumentos de Guerra y Armas de Destrucción Masiva, y otra, sobre Cooperación para la Seguridad Hemisférica.$^{19}$

En esta última se precisa, textualmente, que se resolvió:

1. "Encargar al Consejo Permanente Ia creación de un grupo de trabajo para que estudie y formule recomendaciones referentes a la cooperación para la seguridad hemisférica en sus distintos aspectos."

2.- "Solicitar a los Estados miembros que formulen comentarios en torno al tema y presten su colaboración al grupo de trabajo para el mejor cumplimiento de sus responsabilidades." ${ }^{20}$

$\mathrm{Al}$ año siguiente, en 1992, se dio un significativo avance cualitativo y expansivo en los contenidos relativos a la temática de la seguridad. Ello se reflejó, detalladamente, en Ia Resolución AG/RES, 1179 (XXII - O/92) sobre Cooperación para la Seguridad y el Desarrollo Hemisféricos. Contribuciones Regionales a la Seguridad Global. En ésta se constataba "Que los países democráticos de América Latina y el Caribe son los menos armados y militarizados del mundo". ${ }^{21}$

En línea con el nuevo enfoque y la nueva mentalidad, se resolvió: 1.- " Reconocer la oportunidad y la necesidad de un mayor diálogo sobre temas de seguridad y de cooperación en esta materia entre las naciones del Hemisferio, a la luz de la nueva situación internacional.", y, además: 5.- "Aceptar como principio rector del desarme y de las políticas de control y limitación de armas en el ámbito regional la necesidad de promover la seguridad y la estabilidad con el menor nivel posible de fuerzas acordes con los requerimientos de defensa y los compromisos internacionales."

Además, se instó a los Estados miembros a adoptar un conjunto de 17 medidas contempladas en la Resolución. Dentro de éstas - y en directa ligazón con nuestro tema - se trata de: "b. respaldar los procesos de integración en el hemisferio;.f. apoyar los esfuerzos en el ámbito de las Naciones Unidas y las negociaciones en la Conferencia de Desarme en pro del objetivo de lograr el desarme general y completo bajo control internacional eficaz; n. apoyar y adoptar, según proceda, medidas de fomento de la con-

\footnotetext{
19 Véase en bibliografia, sección documentos: resoluciones ag/res. 1121 (xxi - o/91) y ag/res. 1123 (xxi - o/91). 20 Véase en resolucion ag/res, 1123 (xxi - o/91), op. cit., p. 118.

21 Véase en bibliografia, sección documentos: en resolucion ag/res. 1179 (xxii - 0/92), p. 101.
} 
fianza en relación con las fuerzas armadas convencionales, tales como la notificación previa e invitación a observadores para ciertas actividades militares importantes, el intercambio oportuno de información relevante y el mejoramiento de las vías de comunicación; y, p. apoyar la franqueza y la transparencia proporcionando a las Naciones Unidas información normalizada sobre gastos militares, conforme se ratificó recientemente en la resolución 46/25 de su Asamblea General". ${ }^{22}$

La nueva conceptualización de la seguridad se fue abriendo paso así cada vez más. La política exterior chilena también iría asimilando esta nueva realidad.

El énfasis en la cooperación en la esferca de la seguridad, en vez de la confrontación, fue abriendo nuevas perspectivas para la paz y la seguridad regional. Así, desde el enfoque de la seguridad colectiva - elaborado bajo el esquema de enemigos, agresiones o ataques extrarregionales o extracontinentales - , se fue avanzando hacia una visualización posible de una seguridad cooperativa, entre otros cambios conceptuales y prácticos.

Siempre en el marco de la OEA, el 11 de junio de 1993 se aprobó la Resolución AG/RES. 1237 (XXIII-O/93), referida a la realización de una Reunión de Expertos sobre Medidas de Fomento de la Confianza y Mecanismos de Seguridad en la Región, la cual debería llevarse a cabo en fecha anterior al vigésimo cuarto periodo ordinario de sesiones de la Asamblea General, de 1994.

En los considerandos de esta Resolución, se argumentó que:

"(...) el afianzamiento de la paz y la seguridad en el Hemisferio es uno de los propósitos esenciales de la OEA y que el desarrollo económicosocial y la cooperación entre los Estados miembros son fundamentales para alcanzar esa meta;

"Que los procesos de integración regional y subregional, así como el intercambio de información y experiencias y la profundización de los mecanismos de consulta y cooperación favorecen la promoción de la seguridad y la estabilidad en la región; y

"Que las medidas de fomento de la confianza y los mecanismos de seguridad tienden a la prevención de las posibles causas de conflicto contribuyendo a los esfuerzos para el afianzamiento de la paz y la seguridad". ${ }^{23}$

${ }^{23}$ Véase en bibliografía, sección documentos: en resolucion ag/res. 1237 (xxiii - o/93, p. 116. 
La acordada Reunión de Expertos se realizó en Buenos Aires, del 15 al 18 de marzo de 1994. Un resultado concreto fue la elaboración de un detallado "Listado Ilustrativo de Medidas de Posible Aplicación para Fomentar la Confianza y la Seguridad en el Nivel Bilateral, Subregional y Regional". ${ }^{24}$

Así, en el Vigésimo Cuarto Período Ordinario de Sesiones de la Asamblea General de la OEA, realizado en Belém do Pará, Brasil, del 6 al 10 de junio de 1994, se avanzó decididamente, en la perspectiva que venimos delineando, con la aprobación de tres importantes Resoluciones ligadas estrechamente a nuestro Tema. Ellas son la $A G / R E S .1284$ (XXIV-O/94); AG/RES. 1285 (XXIV-O/94) y AG/RES. 1288 (XXIV-O/94), sobre, respectivamente: Información sobre Gastos Militares y Registro de Armas Convencionales; Junta Interamericana de Defensa, y, Medidas para el Fortalecimiento de la Confianza y la Seguridad en la Región. Esta última, Resolución AG/RES. 1288 (XXIV-O/94), sería muy determinante. ${ }^{25}$

Se iniciaría así, definitivamente, a nuestro juicio y de acuerdo a los hechos posteriores, un nuevo período muy constructivo y productivo en el plano de las reconceptualizaciones de la seguridad, correspondiendo ya a una nueva agenda regional. Algunas de estas reconceptualizaciones propongo sintetizarlas así:

1a.- La orientación básica recogida articuladamente en el TIAR, hace ya más de 50 años, acerca de los imperativos de una seguridad colectiva, ha ido quedando obsoleta en las realidades regionales interamericanas de las Américas, para comenzar a dar paso a la necesidad y viabilidad de una seguridad cooperativa asociativa, en nuestra región sudamericana y en nuestra subregión del Cono Sur de América; ligada al desarrollo económico y social y a los procesos de integración.

2a.- Pensar en una concepción que se orienta hacia la visualización de una región y/o subregión segura, ya no aparece como algo utópico o inalcanzable en tiempos venideros, como fase superior y distinta al clásico enfoque del objetivo nacional natural e inherente a cada Estado - pero insuficiente y limitado hoy en día, insertos en un esquema de integración subregional -, de unas fronteras seguras solamente; lo que demandará, por cierto, la superación de resabios nacionalistas.

24 Vêase, más adelante, en página 45 , nota bibliográfica $71 \%$

25 Véase en bibliografía, sección documentos: resoluciones ag/res. 1284 (xxiv-0/94), pp. 130 y 131; ag/ res. 1285 (xxiv - o/94), pp. 132 y 133, y, ag/res. 1288 (xxiv - 0/94), pp. 138-140. 
3a.-Asimismo, la nueva percepción de que los enemigos extraregionales van dejando paso a desafios comunes intrarregionales, se fue transformando en una potencialidad emergente, que comienza a consolidarse, en la agenda de nuestros Gobiernos, los que a su vez deben incorporarlos en las elaboraciones, formulaciones y puestas en práctica de sus respectivas Políticas Exteriores y de Defensa ; incorporando e informando a las opiniones públicas nacionales en este nuevo enfoque y en los consecuentes emprendimientos emanados de aquel.

4a.- De allí, también, que las antiguas hipótesis de conflicto podrían irse convirtiendo en hipótesis de pazy cooperación, tanto en las actitudes, los conceptos, las conductas, los dichos, los lenguajes, los planeamientos estratégicos de los Estados Mayores, las sensibilidades y tonos institucionales de las Fuerzas Armadas de la región y la subregión, en tanto mentalidades distintivas de nuestras sociedades nacionales; las que deben permeabilizarse y cimentarse en nuevas relaciones de civiles y militares con una mirada de futuro, demostrando confianza.

5a.- En el caso de América Latina y el Caribe, esta región estará dotada para hacer una contribución efectiva a la seguridad global, y por ende, a la paz y la seguridad internacionales, en la medida que vaya construyendo, mediante aproximaciones históricas sucesivas y concretas, basadas en la confianza mutua, una estructuración de subregiones seguras como espacios fundamentales e integrados del conjunto de una seguridad regional, concertada y con consulta política en forma democrática, en la perspectiva del primer decenio del siglo XXI.

Una Conferencia Especial de Seguridad, en el marco de la OEA, a comienzos de la próxima década, culminaría este proceso de reconceptualización.

\section{Medidas de confianza mutua: Antecedentes para propuestas en conferencias regionales ad-hoc}

La cuestión de las Medidas de Confianza Mutua (MCM) demanda, aunque no sea muy brevemente, reseñar aspectos conceptuales y relativos a su origen.

Baste señalar de la propia denominación que utilizo, no es unívoca, tanto en la disciplina académica de las relaciones internacionales como en las 
ciencias militares, ni en su utilización en los organismos intērnacionales. Así también se emplean las expresiones de 'Medidas de Fomento de la Confianza' (como ya hemos visto en el caso de los desarrollos de la OEA y sus instancias especializadas), o bien, de 'Medidas de Confianza y Seguridad', o 'Medidas de Fomento de la Confianza y la Seguridad', entre otros matices. En todo caso, en este trabajo y como propuesta de política exterior y de defensa para Chile, especialmente para nuestras relaciones bilaterales y vecinales, con los estados partes del MERCOSUR, nos parece que el término de Medidas de Confianza Mutua es el más adecuado, expresivo y nítido en significación política y en su aplicación político-estratégica.

Un destacado autor, en la pesquisa acerca de una definición conceptual de las MCM, ha señalado que: "parece existir coincidencia al menos en cuanto a lo que no pueden ser las medidas de confianza. Ante todo, las MCM no son un sistema de seguridad ni una doctrina de seguridad. Dicho de forma más amplia, un conjunto de MCM no forman por sí mismas un sistema de seguridad y no son necesariamente previas o se desprenden obligadamente de un sistema de seguridad." $Y$ agrega, recogiendo los desarrollos consensuados en las Naciones Unidas en 1982, que: "las MCM no sustituyen el control de armamentos ni las medidas de desarme." 26

La ONU precisaba que: "Si se cometiera el error de interpretar que las medidas de fomento de la confianza constituyen un sustituto de las medidas de desarme no sólo se sobrestimaría su potencial positivo intrínseco sino que también podría correrse el riesgo de que se las utilizara como pretexto para evitar reales progresos en el control de armamentos y el desarme, e incluso para legitimar el permanente aumento de armamentos." 27

El autor citado, más arriba, nos aclara, en forma muy acertada, que: "Visto lo que las MCM no pueden o no deben ser, hay que tratar de definirlas en positivo. Existe una definición estricta en sentido instrumental y otra amplia en sentido ontológico. La primera identifica las MCM como mecanismos técnicos que alejan la probabilidad de que un conflicto estalle por accidente, error, malentendido, o percepción equivocada de intenciones. La definición amplia entiende como MCM aquellas medidas que logran incrementar apreciablemente el grado de confianza previamente existente entre dos o más Estados."

\footnotetext{
${ }^{26}$ Véase en bibliografia, sección articulos: Enrique Gomariz, 1994, p. 34 .

${ }_{27}$ Véase estudio amplio sobre las medidas de fomento de la confianza, Naciones Unidas, Nueva York, 1982, p. 8.
} 
Es el mismo quien complementa su necesaria clarificación, al señalar que: "En el ámbito estrictamente militar, una MCM será tal si logra cambiar el status quo de la confianza entre naciones, o dicho de otra forma, si se relaciona de forma efectiva con lo que cada una de ellas considera sus amenazas. Es decir, las MCM no sólo son muestras de cortesía o expresión de buenas relaciones diplomáticas: han de cambiar - o estar pensadas para hacerlo - el nivel previo de la confianza mutua." 28

Por otra parte, un destacado especialista y diplomático, de un país vecino, nos ayuda a remarcar la necesidad e importancia de los aspectos conceptuales, al precisar, ya en 1988, que: "No sería éste un ejercicio puramente académico sino que tendría considerable proyección política en las relaciones internacionales. Emprenderlo representa un desafío para políticos, juristas, economistas y diplomáticos. En el caso de América Latina, su significación no requiere explicaciones." 29

Nuestro país, a través del actual Gobierno, avanzó en la definición de las MCM, como un concepto esencial, precisando, en 1997, que se trata de un: "Acuerdo o compromiso entre dos o más Estados para establecer ciertas acciones tendientes a atenuar las percepciones de amenaza mutua y a evitar situaciones de sorpresa en sus relaciones. Su propósito es prevenir los conflictos, evitando equívocos. Se pueden concretar en el ámbito de la Defensa y también en el económico y el político. Las Medidas de Confianza Mutua contribuyen al proceso de integración." 30

Debemos tener presente, en el desarrollo de esta Sección, que la importancia de las MCM, en la agenda de las Naciones Unidas, había sido enfatizada ya hace más de veinte años, en 1978, desde una perspectiva de la seguridad global y el desarme, al precisar que: "In order to facilitate the process of disarmament, it is necessary to take measures and pursue policies to strengthen international peace and security and to build confidence among States. Commitment to confidence-building measures could significantly contribute to preparing for further progress in disarmament." Para este propósito, propuso tres tipos de medidas, de carácter general, en el marco del Programa de Acción adoptado en la ocasión. ${ }^{31}$

\footnotetext{
28 Vëase op. cit., en nota bibliográfica $25 /$ p. 33.

29 Vêase en bibliografía, sección documentos: Hugo Palma V., 1988, p. 35.

30 Véase en bibliografía, sección libros: Libro de la defensa nacional de Chile, 1997, parte vii, p. 226.

${ }^{31}$ Véase en bibliografía, sección documentos: Resolutions and decisions adopted by the general assembly during its tenth special session, United Nations, 1978, paragraph 93, pp. 10 y 11.
} 
Esbozados algunos aspectos conceptuales básicos relativos a las MCM, es necesario tener información relevante y complementaria acerca del origen, especialmente en cuanto a su puesta en práctica en la arena internacional, en las últimas décadas, desde sus primeras manifestaciones y postulaciones - como expresiones de voluntad política estatal y gubernamental -, particularmente en el escenario de la Europa dividida en dos sistemas sociales y económicos diferentes, desde fin de los años cuarenta, como corolario de la segunda postguerra mundial.

Por tanto, tenemos que remontarnos hasta mediados de los años sesenta en el continente europeo, en la búsqueda de propuestas para alcanzar acuerdos y avances en el ámbito de su seguridad y cooperación, a través del desarrollo de la confianza entre los Estados de los señalados dos sistemas.

Desde el punto del esclarecimiento de la verdad histórica, los resultados reflejados en el Acta de la Conferencia sobre la Seguridad y la Cooperación en Europa, firmada en Helsinki, el $1^{\circ}$ de agosto de 1975, fueron una primera culminación trascendental y muy simbólica para la paz mundial de esfuerzos que habían comenzado con bastante anterioridad, liderados por la ex Unión Soviética.

El primer antecedente documental concreto, sobre una iniciativa política al respecto, surgiría en la Conferencia del Comité Político Consultivo de los Estados signatarios del Tratado de Varsovia sobre la Amistad, la Cooperación y la Ayuda Mutua, realizada en Bucarest, del 4 al 6 de julio de 1966. Su expresión se concretó en la Declaración relativa al fortalecimiento de la Paz y de la Seguridad de Europa, que en su Punto Séptimo, planteó que: "La convocatoria de una conferencia europea para discutir los medios para garantizar la seguridad en Europa y para organizar la cooperación europea sería muy positiva. El acuerdo alcanzado en esta Conferencia podría expresarse, por ejemplo, bajo la forma de una declaración europea sobre la cooperación en el interés del mantenimiento y del fortalecimiento de la seguridad europea."

El planteamiento se fundamentaba agregando que: "La convocatoria de esta conferencia sobre los problemas de la seguridad y de la cooperación europea podría contribuir a la creación de un sistema de seguridad colectiva en Europa y sería un hito destacado en la historia contemporánea de Europa. Nuestros países están listos para participar en una tal conferencia en todo momento conveniente para los otros países interesados, ya sean países 
signatarios del Tratado del Atlántico Norte o países neutrales. Los países europeos neutrales podrían jugar igualmente un rol positivo en la convocatoria de esta conferencia." 32

Las iniciativas en pos del objetivo sintetizado en los párrafos precedentes se reiteraron en 1969, en dos ocasiones, a través del Llamamiento de Budapest (del 17 de marzo) ${ }^{33}$, $\mathrm{y}$, la Declaración de Praga (del 30 de octubre) ${ }^{34}$. También hay que consignar el Memorándum de Budapest (del 22 de junio de 1970) ${ }^{35}$ y la Declaración de Praga sobre la Paz, la Seguridad y la Cooperación en Europa (del 26 de enero de 1972) ${ }^{36}$.

Conocido es que el Acta de Helsinki, de 1975, dentro de las "Cuestiones relativas a la Seguridad en Europa", adoptó la Declaración sobre los Principios Rectores de las Relaciones entre los Estados Participantes. El IX Principio se refiere a la Cooperación entre los Estados. Su texto debe conocerse.

En este IX Principio se estableció que los Estados participantes en la Conferencia de Helsinki: "Procurarán, al desarrollar su cooperación como iguales, promover la comprensión y confianza mutuas, las relaciones amistosas y de buena vecindad entre ellos, la paz internacional, la seguridad y la justicia." 37

El proceso, cuya primera gran culminación histórica había sido en Helsinki, no se detuvo y se prolongaría hasta comienzos de la presente década de los noventa, en su formato inicial. Se celebraron Conferencias sobre la Seguridad y la Cooperación en Europa (CSCE) en Belgrado (1977-1978); en Madrid (1980-1983); en Viena (1986-1989), y, nuevamente en Helsinki (1992). En 1990, se había realizado una Cumbre Especial de la CSCE en París, que culminó con la adopción de la Carta de París para una Nueva Europa.

Asimismo, como resultado de la Conferencia de Madrid, se realizó en Estocolmo una Conferencia sobre Medidas destinadas a Fomentar la Confianza y la Seguridad y sobre Desarme en Europa, la que culminó con la adopción de su Documento Final el 19 de septiembre de 1986. En éste, los Estados signatarios del Acta Final de Helsinki adquirieron nuevos com-

\footnotetext{
32 Vêase en bibliografia, sección documentos: documents de la Conférence de Bucarest, 1966, pp. 2-18. 33 Véase texto íntegro, en Les Nouvelles de Moscou, $n^{\circ} 12,22$ mars 1969, pp. i y 3.

34 Véase texto íntegro, en Les Nouvelles de Moscou, $n^{\circ} 45,8$ novembre 1969, p. 6.

35 Vẻase texto integro, en Les Nouvelles de Moscou, supplément au numéro 27, 4 juillet 1970, pp. 9 y 10.

${ }^{6}$ Vëase texto íntegro, en Les Nouvelles de Moscou, supplément au numëro 6, 5 février 1972, pp. 2-5.

37 Véase en bibliografía, sección documentos: acta final de la Conferencia sobre la seguridad y la cooperacion en Europa. Helsinki, $1^{\circ}$ de agosto de 1975 , pp. 236 y 237.
} 
promisos a través de nuevas Medidas de Fomento de la Confianza (MFC), que por el mandato de Madrid "debían ser militarmente significativas y políticamente vinculantes e incluir mecanismos apropiados de verificación.", lo que se expresó en prolongación, por ejemplo, del "período de notificación previa de maniobras de gran escala, reduciendo la magnitud de las operaciones a notificar y conviniendo en inspecciones no denegables de actividades e instalaciones militares." 38

Un punto de vista, respecto a este 'salto' cualitativo de las MFC, lo expresó un autor ya citado anteriormente, cuando señala que: "Evidentemente, las medidas de Estocolmo son mucho más significativas e importantes que las de Helsinki y han sido denominadas por ello como de "segunda generación", para distinguirlas también cualitativamente de las que en 1975 se referían exclusivamente a algunos aspectos de información." 39

El proceso siguió su desarrollo cualitativo, con ajustes y ampliaciones en conferencias posteriores que, más adelante, dieron paso a los Documentos de Viena (DV) de 17 de noviembre de 1990 y de 4 de marzo de 1992, los que incluyeron, como nuevo avance, las inspecciones in situ.

Posteriormente, el 22 de septiembre de 1992 se estableció un Foro para la Cooperación en Seguridad (FCS), como órgano permanente. Este Foro adoptó nuevas medidas en noviembre de 1993. Al año siguiente, la institucionalidad europea, en esta esfera se transformaría, consolidándose y adquiriendo nuevos roles en los asuntos internacionales del área y constituyéndose en nueva instancia de interlocución.

En efecto, en la Cumbre de la CSCE celebrada en Budapest del 5 al 7 de diciembre de 1994, se adoptó el cambio de nombre de la CSCE, pasando a constituirse en la Organización para la Seguridad y la Cooperación en Europa (OSCE). Ya se trataba de una nueva Europa, que tenía ante sí la posibilidad de iniciar la edificación de una nueva casa comín europea, ahora ya sin dos sistemas sociales y económicos diferentes en permanente confrontación y desconfianza.

Y una modificada versión del Documento de Viena, del 28 de noviembre de 1994, dio cuenta de la nueva situación estipulando las $M F C$ actualmente en vigor.

${ }^{38}$ Véase en bibliografía, secciốn documentos: diálogo Union Europea- Grupo de Río sobre medidas de fomento de la confianza mutua, 1995, p. 7.

39 Vẻase en bibliografia, secciôn documentos: hugo palma v., op. cit., 1988, p. 12. 
A modo de síntesis informativa - a ser tenida en cuenta para las experiencias de nuestra región -, indicaremos las diez Secciones del DV'94, en referencia. Ellas son las siguientes: ${ }^{40}$

- Intercambio anual de información militar;

- Reducción de riesgos;

- Contactos;

- Notificación previa de determinadas actividades militares;

- Observación de determinadas actividades militares;

- Calendarios anuales;

- Disposiciones restrictivas;

- Observancia y verificación;

- Comunicaciones;

- Reunión anual de evaluación de la observancia.

Estos antecedentes configuran, sumariamente, el origen europeo, en un contexto histórico distinto y con un determinado enfoque, de la problemática de las Medidas de Confianza Mutua.

Ahora bien, si en el caso del contexto internacional europeo, en la pesquisa de antecedentes sobre las MCM tuvimos que retroceder algo más de tres décadas, en la situación de nuestra región latinoamericana debemos hacerlo igualmente, a lo menos, por algo más de dos décadas.

Es así que a mediados de la década de los setenta -curiosamente en contextos nacionales y regional mayoritariamente no democráticos, desde el punto de vista de los sistemas políticos-, se encuentran los inicios de la exploración de nuevos enfoques para cambiar progresivamente los ambientes cargados de recelos acendrados y desconfianzas históricas en los Estados y sociedades de la región. En los años 1974-1976 se encuentran los primeros antecedentes de aproximaciones hacia la confianza mutua, impulsados, paradójicamente, por gobiernos encabezados por militares, con el respaldo de las respectivas Fuerzas Armadas de cada país involucrado.

Dos son los principales antecedentes que es necesario registrar, en la perspectiva de seguir apoyándonos en el rigor investigativo y la prolijidad analítica.

Se trata, en primer lugar de la Declaración de Ayacucho, firmada en Lima, Perú, el 9 de diciembre de 1974, en el Sesquicentenario de la Batalla de 
Ayacucho, por los Jefes de Estado o sus representantes de Argentina, Bolivia, Colombia, Chile, Ecuador, Panamá, Perú y Venezuela. ${ }^{41}$

En segundo término, nos referimos al Acuerdo de Cooperación para el Afianzamiento de la Paz y la Amistad entre las FF.AA. de las Repúblicas de Bolivia, Chile y Perí, firmado en Santiago de Chile, el 27 de mayo de 1976, por altos representantes de las distintas ramas de las Fuerzas Armadas de los tres países indicados ${ }^{42}$

Ciertamente, son dos documentos fundamentales que no deben ignorarse, aún en retrospectiva histórica, ya que se ligan a las fuentes de nuestro tema.

Es así, que gracias a exploraciones y negociaciones concretas, dimanantes del desarrollo ulterior de la Declaración de Ayacucho, se avanzó en la elaboración de diez posibles medidas para su adopción por parte de las Fuerzas Armadas, siendo extensivas algunas de ellas a la participación de las respectivas fuerzas policiales nacionales de cada país. Esto en tiempos de regímenes militares se consideraba como algo natural o inherente. Los contenidos de estas medidas, en su formulación, lenguaje y explicitación posterior, coincidirían con las MCM que se han implementado entre Chile y Perú, desde 1986, y entre Chile y Argentina, desde 1994.

Por ello, vale detenerse en el detalle de los contenidos de algunos Artículos del Acuerdo de Cooperación de 1976, con una estructura contractual muy precisa.

-ART. 2: “Las Fuerzas Armadas de Bolivia, Chile y Perú cooperarán mutuamente para el afianzamiento de la paz entre ellos mediante la creación de un procedimiento de consultas que atenderá los aspectos d cooperación militar destinados a resolver los problemas que puedan presentarse en sus relaciones recíprocas."

- ART. 4: "Las Fuerzas Armadas de Bolivia, Chile y el Perú acuerdan establecer un intercambio de informaciones a fin de contribuir a descartar situaciones que puedan devenir conflictivas y a eliminar apreciaciones erróneas sobre las actividades militares en las zonas fronterizas.", $\mathrm{y}$,

- ART. 5: "Las Fuerzas Armadas de Bolivia, Chile y el Perú se comprometen a:

41 Véase en bibliografía, secciôn documentos: Declaracion de Ayacucho, 1974.

${ }^{42}$ Véase en bibliografia, sección documentos: Acuerdo de Cooperacion para el afianzamiento de la paz y la amistad entre las FF.AA. de las Republicas de Bolivia, Chile y Peru, 1976. 
a.- Llevar a cabo medidas conjuntas para el afianzamiento de la amistad y la paz, creando un clima de confianza en la opinión pública y el respeto mutuo, base sustancial para la cooperación entre los Gobiernos.

b.- Promover la comprensión y las relaciones de amistad y vecindad, sobre todo mediante acciones de cooperación, especialmente en las áreas fronterizas.

c.- Desarrollar la cooperación militar entre ellos, en un pie de igualdad y respeto mutuo." 43

Así se fue adaptando el contexto regional para la implementación de MCM.

Situados ya en los comienzos de los años noventa, y con todos los antecedentes sistematizados en esta sección y en la sección II, podemos comprender de mejor manera como se va avanzando hacia la formulación de MCM en nuestra región, bajo el ámbito institucional y la iniciativa incubada en el seno de la OEA, a través de diversos períodos ordinarios de sesiones de su Asamblea General.

Como lo diéramos a conocer con anterioridad, es en la Resolución AG/ RES. 1179 (XXII-O/92) donde se comienza a especificar la preocupación por el Tema de las MCM. En el Punto 6. letra n., se insta a todos los Estados miembros a:

"apoyar y adoptar, según proceda, medidas de fomento de la confianza en relación con las fuerzas armadas convencionales, tales como la notificación previa o invitación a observadores para ciertas actividades militares importantes, el intercambio oportuno de información relevante y el mejoramiento de las vías de comunicación", y, en la letra p. se insta a:

"apoyar la franqueza y la transparencia proporcionando a las Naciones Unidas información normalizada sobre gastos militares, conforme se ratificó recientemente en la resolución 46/25 de su Asamblea General." 44

Como ya sabemos, en Managua, el 11 de junio de 1993, se adoptó la Resolución AG/RES. 1237 (XXIII-O/93), relativa a la realización de una Reunión de Expertos sobre Medidas de Fomento de la Confianza y Mecanismos de Seguridad.

$\mathrm{Al}$ año siguiente, el camino - que culminaría en la realización de las Conferencias Regionales ad hoc - se fue diseñando en forma cada vez más concreta. Esto se formalizó a través de la Resolución AG/RES: 1288 (XXIV-

43 lbidem, pp. 1211 y 1212. 
O/94) sobre Medidas para el Fortalecimiento de la Confianza y la Seguridad en la Región.

En ésta, se resolvió, entre algunos de sus Puntos específicos, lo siguiente:

3.- "Continuar, por medio de la Comisión Especial de Seguridad Hemisférica del Consejo Permanente, el examen de las cuestiones del fortalecimiento de la confianza y, entre otras, las relativas a la solución pacífica de controversias y la prevención de los conflictos, dentro del marco del principio del respeto a la plena vigencia del derecho internacional, así como de los entendimientos jurídicos y políticos bilaterales, subregionales y regionales existentes."

4.- "Recomendar a los estados miembros que pongan en práctica, en el nivel pertinente y por los medios que ellos estimen adecuados, medidas de fomento de la confianza, y que informen regularmente a las instancias competentes de la OEA sobre la aplicación de dichas medidas."

5.- " Encargar al Consejo Permanente que, por medio de la Comisión Especial de Seguridad Hemisférica y para dar continuidad al ejercicio iniciado en la Reunión de Buenos Aires, confeccione un inventario completo y sistemático de las medidas de fomento de la confianza que se vienen aplicando en el Hemisferio, con miras a su difusión, mejor conocimiento y más fácil adopción y aplicación a nivel bilateral, subregional y hemisférico."

Y, por último, un punto muy significativo para nuestro país, en lo concreto:

6.- "Proseguir, con base en las observaciones de los gobiernos, las consultas en el seno de la OEA tendientes a determinar la celebración, en 1995, de una Conferencia Regional sobre Medidas de Fomento de la Confianza y Seguridad en la Región, cuya sede ha sido ofrecida por Chile." 45

Igualmente relevante es conocer una Resolución muy importante - la $C P$ / RES. 650 (1031/95) -, aprobada por el Consejo Permanente de la OEA, el $1^{\circ}$ de junio de 1995, y denominada Junta Interamericana de Defensa. Allí se resolvió:

1.- " Requerir a la Junta Interamericana de Defensa que, en los términos establecidos por la resolución AG/RES. 1288 (XXIV-O/93), - (referida y detallada en párrafos precedentes) - evalúe la posibilidad de elaborar un proyecto de inventario completo y sistemático de las medidas de fomento de la confianza de naturaleza militar que se vienen aplicando en el Hemisferio ",

\footnotetext{
44 Véase en bibliografía, secciôn documentos: resolucion ag/res. 1179 (xxii-o/92), p. 104.

45 Véase en bibliografía, sección documentos: resolucion ag/res. 1288 (xxiv•0/94), pp. 139 y 140.
} 
2.- "Solicitar a la Junta Interamericana de Defensa que, una vez elaborado dicho proyecto de inventario, lo someta al Consejo Permanente para su consideración, y de ser el caso, posterior presentación en la "Reunión Preparatoria de la Conferencia sobre Medidas de Fomento de la Confianza y la Seguridad", a celebrarse en Washington, en el mes de septiembre próximo." 46

De la forma descrita, y contenida en los antecedentes previos, se llegó, a través de un riguroso proceso en la OEA, que se fue caracterizando por la escrupulosa aplicación, cumplimiento e implementación de las Resoluciones de la Asamblea General y del Consejo Permanente, a la celebración de la Conferencia Regional de Santiago sobre Medidas de Fomento de la Confianza y de la Seguridad, entre los días 8 a 10 de noviembre de 1995. Nuestro país tuvo el honor de presidirla, a través de su Jefe de Delegación, el Embajador Pablo Cabrera Gaete, actual embajador de Chile en Gran Bretaña.

La Declaración de Santiago reflejó en sus contenidos muy valiosos avances.

Algunos de éstos son los siguientes. Así postuló que: "los Estados miembros de la OEA continúen el necesario proceso de reflexión para eliminar los factores que generan desconfianza entre los Estados del hemisferio y para identificar nuevas modalidades de colaboración ...". "La adopción de medidas de fomento de la confianza y de la seguridad constituye una contribución importante a la transparencia, entendimiento mutuo y a la seguridad regional ...". "Las medidas de fomento de la confianza y de la seguridad deben adaptarse a las condiciones geográficas, políticas, sociales, culturales y económicas de cada región y tienen su propio ámbito de aplicación ...". "La aplicación de medidas de fomento de la confianza y de la seguridad contribuye a la creación de un ambiente propicio para una efectiva limitación de armamentos convencionales que permita dedicar un mayor número de recursos al desarrollo económico y social de los Estados miembros, el cual es un propósito esencial de la Carta de la OEA.". "Las medidas que apuntan al fomento de la confianza y de la seguridad en las Américas son especialmente significativas para la estructuración de relaciones de amistad y cooperación."

Por último, la Conferencia de Santiago acordó recomendar: "la aplicación de la manera que sea adecuada a cada país, de medidas de fomento de la confianza y de la seguridad, entre las cuales" explicitó, puntualizada-

${ }_{46}^{46}$ Vease en bibliografia, sección documentos: resolucion cp/res. 650 (1031/95), anexo, p. 25. 
mente, un total de $11 \mathrm{MCM}$, las que "requieren la puesta en marcha de una serie de acciones tendientes al seguimiento y periódica evaluación de su implementación." ${ }^{47}$

La OEA siguió sus tareas en esta esfera, a través de las Resoluciones AG/RES. 1409 (XXVI-O/96), aprobada el 7 de junio de 1996, y AG/RES. 1494 (XXVII-O/97), aprobada el 5 de junio de 1997, bajo la denominación específica común de MEDIDAS DE FOMENTO DE LA CONFIANZA Y DE LA SEGURIDAD DE LAS AMERICAS. Y en 1998, se trata de las Resoluciones AG/RES. 1566 (XXVIII-O/98) y AG/RES. 1570 (XXVIII-O/ 98), aprobadas el 2 de junio de 1998, y, AG/RES. 1604 (XXVIII-O/98), aprobada el 3 de junio de 1998. ${ }^{48}$

La Declaración de San Salvador sobre Medidas de Fomento de la Confianza y de la Seguridad, de febrero de 1998, reafirmó la profundización que la materia ha ido adquiriendo, en la perspectiva de avanzar en la construcción de una seguridad regional, mediante su reconceptualización, y representó un gran avance cualitativo.

La Tercera Conferencia de Ministros de Defensa de las Américas, realizada en Cartagena de Indias, Colombia, del 29 de noviembre al 3 de diciembre de 1998, valoró todos estos progresos, al sostener en su $D e$ claración, Punto 5. "Que la adopción de medidas de fomento de la confianza y seguridad ha fortalecido el entendimiento mutuo y ha contribuido a la seguridad regional, al desarrollo económico y social y a la integración hemisférica." 49

Finalmente, este Material de Discusión contiene un ANEXO 2, en páginas 39 y 40 , con la textualidad de las $11 \mathrm{MCM}$ cuya aplicación se acordó recomendar en la Conferencia de Santiago, de noviembre de 1995, y de las nuevas 9 MCM sumadas y recomendadas en la Conferencia de San Salvador, de febrero de 1998.

${ }_{47}$ Véase en bibliografía, sección documentos: Declaracion de Santiago sobre medidas de fomento de la confianza y de la seguridad, 1995, pp. 58-60.

${ }^{48}$ Véase en bibliografía, secciôn documentos: resoluciones ag/res. 1409 (xxvi-o/g6); ag/res. 1494 (xxviio/97); ag/res. 1566 (xxviii-o/98) y ag/res. 1570 (xxviii-o/98).

49 Véase "declaracion de cartagena". Tercera Conferencia de Ministros de Defensa de las Americas, Cartagena de Indias, República de Colombia, 2 de Díciembre de 1998, p. 2. 


\section{Nuevas vinculaciones de Chile en el MERCOSUR}

Ciertamente, puede afirmarse, con sólidos fundamentos provenientes de los hechos de la realidad, que a partir de 1994-1995 se inician nuevos énfasis en las aproximaciones de Chile hacia el MERCOSUR, las que adquieren un nuevo interés recíproco y nuevos dinamismos diversificadores, en tanto nuevas vinculaciones desarrolladas desde 1996-1997. La expresión práctica de esta voluntad política del Gobierno de Chile se va haciendo más multifacética durante 1998, y se proyecta como una nueva prioridad de la Política exterior Chilena para 1999, más allá de los "aspectos exclusivamente comerciales y económicos".

Una singular indicio de esta prioridad, resultante de la voluntad política gubernamental, se manifestó públicamente a fines de diciembre de 1998, por parte del actual Ministro de Relaciones Exteriores de Chile. En la ocasión, el Canciller sostuvo lo siguiente: "Creo que se mantiene bien nuestra relación con el Mercosur, y aprovecho de decir que nosotros esperamos que en 1999 demos pasos muy decisivos para un acercamiento mayor al Mercosur. Creo que este acuerdo ha alcanzado un nivel de gran importancia para nosotros, y se ha demostrado que no sólo se trata de un acuerdo arancelario, sino que abarca un conjunto de otros temas $y$, por lo consiguiente, pensamos que desde el punto de vista estratégico, no considerando sólo un punto - si los aranceles son mayores o menores - sino que desde un punto de vista estratégico más general, un avance en la dirección de una mayor incorporación en el Mercosur sería más importante antes de fin de siglo." Y más adelante, hizo la precisión siguiente: "Yo creo que si me pregunta cual es la prioridad de la política exterior de Chile, lo principal es como lograr su plena integración dentro del marco del Mercosur y América Latina. Esto debería ser fijado como nuestra prioridad permanente, no sólo por razones económicas, sino por razones estratégicas." 50

¿Cómo se llegó a esta nueva situación y prioridad postulada para la Política exterior Chilena, en sus vinculaciones con el MERCOSUR? Ahora lo analizamos.

A mediados de estos años noventa, parecía que el nuevo Gobierno privilegiaba básicamente, en su inserción internacional, las relaciones comer-

so Vêase en bibliografia, secciôn documentos: conferencia de prensa , 1998, pp. 2 y 11. 
ciales y económicas internacionales, en un atinado proceso de búsqueda y diversificación de mercados, tanto para nuestras exportaciones como para nuestras importancias. De allí que se hablara de una equilibrada inserción y distribución en tres grandes mercados/zonas geográficas: Europa, AsiaPacífico y las Américas, en lo principal, desde el punto de vista de los intercambios comerciales. En el caso particular de América Latina, podríamos señalar que se trató de una creciente reinserción en su mercado, que había sido despreciado o no privilegiado en los años ochenta. $Y$ en esta región, el MERCOSUR se estableció en 1991 y' se institucionalizó en 1994.

En otro gran ámbito de su inserción internacional, el Gobierno se propuso que Chile ocupara uno de los dos cupos latinoamericanos entre los Miembros No Permanentes del Consejo de Seguridad de las Naciones Unidas, para lo cual necesitaba contar con el apoyo mayoritario del Grupo Latinoamericano y Caribeño (GRULAC) de la ONU. Este objetivo político se alcanzó, y es así que Chile ocupó dicha plaza durante los años 19961997, intensificando su participación en diversas instancias de las Naciones Unidas, como lo es la Asamblea General y el ámbito clave del Consejo Económico y Social (ECOSOC), entre sus órganos principales.

Simultẩneamente, Chile se veía confrontado a su activa participación, en diversas ocasiones, en las Cumbres - esencialmente dedicadas a la concertación, la consulta y el diálogo político - del Grupo de Río, las Iberoamericanas y las de las Américas, siendo, incluso sede de éstas últimas en el período reciente. De allí que la multiplicación de ingentes esfuerzos en la esfera propiamente político-diplomática, fueron haciendo retomar una tradición de la presencia internacional chilena y simultáneamente equilibrando su inserción internacional, que aparecía erróneamente demasiado marcada sólo por objetivos comerciales y económicos.

Paralelamente, el MERCOSUR comenzó a profundizar el desarrollo de su pre-sencia externa y el establecimiento de sus relaciones exteriores, al ir logrando su reconocimiento como un importante interlocutor institucionalizado en la escena internacional. Y superando claramente la estrecha y limitada visión de que sólo era una llamativa, novedosa y rápida constitución de una simple unión aduanera, que se encaminaba, como proyecto de integración hacia un mercado comuin, en el Cono Sur de América; él que se inscribiría rutinariamente - desde el punto de vista histórico - en los diversos y no muy exitosos emprendimientos de la integración la- 
tinoamericana, que se venían intentando desde los años cincuenta en la región.

Otro factor significante de las visualizaciones de la política exterior chilena, en estos años recientes, está dado por la retomada y clarificada conciencia acerca de la esencia de las relaciones bilaterales vecinales, como un elemento cardinal e inmanente de nuestro desarrollo nacional, la paz y la seguridad, la buena vecindad y la solución pacífica de las controversias aún pendientes con nuestros tres países vecinos. En el caso de Argentina, en particular, se trataba de un miembro fundador y Estado parte relevante del MERCOSUR. Bolivia, por su parte, antes que Chile, ya había iniciado un proceso de acercamiento, desde 1992, como país interesado en el proyecto de integración del MERCOSUR, siendo un elemento geoestratégico clave para la temática de su enclaustramiento y mediterraneidad, por cierto, desde el punto de vista histórico de sus conocidos intereses nacionales.

Y el nuevo fenómeno económico de esta década - la inversión privada chilena en el extranjero y especialmente en países miembros del MERCOSUR -, fue otra variable dinamizadora y complementaria de la correcta visualización sobre los alcances y proyecciones de este nuevo esquema de integración económica.

Es en este contexto de la puesta en práctica de la política exterior Chilena, durante el bienio 1994-1995, que se comienzan a desarrollar e implementar nuevas vinculaciones de Chile con el MERCOSUR. Por cierto la suscripción del Acuerdo de Complementación Económica ChileMERCOSUR, el 25 de junio de 1996, fue la expresión más concreta y elaborada, en cuanto a los "aspectos exclusivamente comerciales y económicos ", del nuevo relacionamiento.

A la vez, debemos recordar que ya en la VI Reunión del Consejo del Mercado Común - la instancia máxima del MERCOSUR, siempre con la participación de los Presidentes de sus Estados partes -, realizada en Buenos Aires, el 5 de agosto de 1994, se había contado con la presencia, como invitado especial, del Presidente Eduardo Frei Ruiz-Tagle.

En la ocasión, se firmó la importante Declaración de los Presidentes del MERCOSUR y de la República de Chile. En ella se estipula que ellos: "Deciden en esta oportunidad iniciar, a la brevedad, negociaciones para suscribir un acuerdo de complementación económica entre el MERCOSUR y la República de Chile, para la constitución de un área de libre comercio." 
Igualmente: "Convienen por último que Chile participe como observador en grupos de trabajo a ser acordados oportunamente con los países del MERCOSUR." 51

El Presidente Frei Ruiz-Tagle volvería a estar presente, como invitado especial, en la VIII Reunión del Consejo del Mercado Común (CMC), realizada en Asunción, el 5 de agosto de 1995.

Es en la X Reunión del Consejo del Mercado Comin, realizada en la localidad de Potrero de Los Funes, Provincia de San Luis, Argentina, el 25 de junio de 1996, donde vuelve a contarse con la presencia del Presidente Frei Ruiz-Tagle. La ocasión era muy relevante, dada la suscripción del ACUERDO DE COMPLEMENTACION ECONOMICA CHILE MERCOSUR. Así se dejó constancia en el Conunicado de los Presidentes del MERCOSUR. En su Punto 6., éstos: "manifestaron su profunda satisfacción por la conclusión del Acuerdo de Complementación Económica con la República de Chile que crea una zona de libre comercio con el MERCOSUR. Este trascendente instrumento, que abarcará lo sustancial del comercio recíproco en un plazo de ocho años, permitirá enriquecer e intensificar las privilegiadas relaciones que cada uno de los Estados partes mantienen con esa Nación andina." 52

Asimismo, en esta X Reunión del CMC, los Presidentes del MERCOSUR suscribieron un importante documento, que comenzaría a abrir, definitivamente, el ámbito de sus preocupaciones más allá de los "alcances exclusivamente comerciales y económicos ". Se trató de la Declaración sobre Compromiso Democrático en el MERCOSUR. ${ }^{53}$

El Presidente Frei Ruiz-Tagle, y el Presidente de Bolivia, firmaron un Protocolo de Adhesión a dicha Declaración, donde manifestaron que: "en lo que se refiere a los acuerdos celebrados o a celebrarse entre sus respectivos Estados con el MIERCOSUR o con sus Estados partes, será de aplicación el principio democrático como condición esencial para la continuidad del proceso de integración en curso." 54

Otro documento relevante fue firmado por los Presidentes del MER-

52Vêase en bibliografía, sección documentos: declaracion de los presidentes del MERCOSUR y de la República de Chile, 1994, pp. 94 y 95.

${ }^{22}$ Véase en bịliografia, sección documentos: en Boletîn Oficlal del MERCOSUR, 1997, p. 106.

s3 Véase en op. cit., 1997, pp. 108 y 109.

54 Ibídem, p. 109. 
COSUR, en la misma ocasión. Se trató de la Declaración Presidencial sobre Diálogo Político entre los Estados partes del MERCOSUR. En lo principal, los Presidentes deciden:

$1^{\circ}$.- "Establecer entre los Estados partes del MERCOSUR un Mecanismo de Consulta y Concertación Política con los siguientes propósitos:

A).- Ampliar y sistematizar la cooperación política entre los Estados partes.

B).- Examinar las cuestiones internacionales de especial interés para los Estados partes con el objetivo de buscar concertar posiciones en relación a las mismas, $y$

C).- Considerar asuntos de interés político común relacionados con terceros países, grupos de países u organismos internacionales." 55

Así también, en la señalada $X$ Reunión del $C M C$, los Presidentes de los Estados partes del MERCOSUR y de la República de Bolivia y de la República de Chile suscribieron una significativa "Declaración sobre Malvinas ". 56

La presencia del Presidente Frei Ruiz-Tagle, como invitado especial, se repetiría en la XI Reunión del CMC, realizada en Fortaleza, Brasil, el 17 de diciembre de 1996. En esta ocasión se adoptó la importante Decisión MERCOSUR/CMC/DEC. $N^{\circ}$ 14/96, sobre Participación de Terceros Países Asociados en Reuniones del MERCOSUR. ${ }^{57}$

A partir de la XII Reunión del CMC, realizada en Asunción, el 19 de junio de 1997, el Presidente Eduardo Frei Ruiz-Tagle ha participado regularmente en esta instancia máxima del MERCOSUR, junto con una Delegación oficial chilena.

En la XII Reunión del CMC se tomó una Decisión sobre la Participación de Chile en el Mecanismo de Consulta y' Concertación Política del MERCOSUR. 58

Y es en la XIII Reunión del CMC, realizada en Montevideo, el 15 de diciembre de 1997, que se adoptó la Decisión MERCOSUR/CMCDEEC. $N^{\circ} 12 / 97$, relativa a la Participación de Chile en Reuniones del MERCOSUR. ${ }^{59}$

\footnotetext{
35 Ibídem, pp. 109 y 110.

${ }^{56} \mathrm{lbidem}, \mathrm{pp} .110$ y 111.

57 Véase texto întegro decision mercosur $/ \mathrm{cmc} / \mathrm{dec}$. $\mathrm{n}^{\circ} 14 / 96$, xi cmc - Fortaleza, 17/12/96, $2 \mathrm{p}$.

${ }^{88}$ Véase texto íntegro de la declaracion presidencial sobre la consulta y concertacion politica. Asunción, 17 de junio de 1997: en boletín oficial del MERCOSUR, op. cit., 1997, pp. 118 y 119.

59 Véase texto integro decision mercosur/cm/dec. $n^{\circ}$ 12/97, xiii cmc - Montevideo, 25/12/97, 3 p.
} 
Así se fue consolidando la amplia perspectiva de una nueva vinculación de Chile con el MERCOSUR, en la esfera de la concertación, consulta y diálogo políticos, abriéndose enormes potencialidades para buscar nuevas de esferas de colaboración, cooperación e intercambio, como parte sustantiva de las elaboraciones, formulaciones y puesta en práctica de las Políticas Exterior y de Seguridad y Defensa de Chile.

El incremento y desarrollo de los propios alcances del MERCOSUR, como un proyecto de integración multifacético, se materializó en forma sustantiva durante las XIV y XV Reuniones del Consejo del Mercado Común, realizadas, respectivamente, en Ushuaia, Argentina, el 24 de julio de 1998, y en Río de Janeiro, el 10 de diciembre de 1998, con plena participación de Chile, tanto a nivel presidencial como de una importante Delegación oficial.

Del mismo modo, Chile ha comenzado a intensificar su participación en sub-grupos de Trabajo, en Grupos ad hoc, en reuniones especializadas y reuniones de ministros, y en las correspondientes reuniones técnicas preparatorias. $Y$, por cierto, Chile ha participado en numerosos debates de los doce foros cuya competencia se relaciona con los temas del $A C E N^{\circ} 35$, así como en las reuniones regulares de la Comisión Administradora del mismo.

Además, la Decisión $N^{\circ} 12 / 97$, contempló, en su Artículo 6. que:

"En materia de relaciones externas Mercosur y Chile:

a) Establecerán coordinaciones regulares en todas aquellas negociaciones que se entiendan de interés de ambas partes, incluyendo, cuando sea el caso, misiones externas que éstas realicen.

b) Intercambiarán experiencias, al menos dos veces al año, sobre las diversas negociaciones en curso."

Además, en su Artículo 8. estipuló que: "La presente Decisión podrá ser objeto de perfeccionamiento a fin de permitir que la modalidad de relacionamiento entre Mercosur y Chile acompañe la evolución y profundización del proceso de integración entre las partes." 60

Es más: la XIV Reunión del CMIC, de julio de 1998, culminó con la eminente Declaración Política del MERCOSUR, Bolivia y' Chile como Zona de Paz. ${ }^{61}$

Por último, esta Sección IV debe complementarse, en sus contenidos, 
con el ANEXO 1, que se encuentra en las páginas 36 a 38, y que incluye una detallada y actualizada CRONOLOGIA BASICA DE LA VINCULACION DE CHILE CON EL MERCOSUR, desde Agosto 1994 a Diciembre 1998.

\section{Hacia una seguridad subregional y vecinal amable}

Del conjunto de antecedentes y contenidos expuestos y detallados en las Secciones II, III y IV precedentes, sobre reconceptualizaciones de Ia seguridad, medidas de confianza mutua y nuevas vinculaciones de Chile con el MERCOSUR, podemos postular que la Política exterior Chilena se oriente hacia la estructuración de un esquema de seguridad subregional y vecinal, en el contexto del actual proceso de integración en el Cono Sur de América, hacia el período 2000-2010.

Existen ya sólidos argumentos, experiencias, instrumentos y mecanismos que permiten sustentar una postulación como la que proponemos:

- Las oportunidades y posibilidades son mayores que los obstáculos;

- Las ventajas se visualizan mejores en desmedro de las desventajas;

- Los nuevos conceptos se abren paso y doblegan a los viejos prejuicios;

- Las nuevas confianzas mutuas desplazan a las desconfianzas históricas;

- La integración y cooperación avanzan por sobre divisiones y confrontaciones;

- La concertación política y el diálogo político democrático se sobreponen a las incomunicaciones nacionalistas y las perversiones históricas pro militaristas;

- La paz y la solución pacífica de las controversias pendientes se imponen a los riesgos de guerra y los enfrentamientos armados por conflictos limítrofes;

- Las Fuerzas Armadas encaran y perfeccionan un proceso de modernización;

- La transparencia informativa y homologación sobre gastos militares avanzan.

Mas, sabemos que hoy, ciertamente, los pueblos de la subregión del Cono Sur no transitan por las amplias y fáciles avenidas pavimentadas de la historia:

- Las injusticias sociales y los abusos del poder abundan y se incrementan; 
- La pobreza es el amanecer de la vida cotidiana individual y familiar de millones de seres humanos, con limitados accesos a la educación y salud;

- Las discriminaciones y exclusiones de las poblaciones aborígenes y las comunidades indígenas son aún, en los distintos países, avasallantes;

- Las economías nacionales dependientes están expuestas a múltiples vulnerabilidades y a imprevisibles fluctuaciones financieras especulativas;

- La cultura y los valores comunes idiosincráticos de nuestras sociedades son irrespetados aplastantemente por las influencias y las ondas globalizadoras;

- La ciencia y la tecnología son controladas centralmente y transferidas condicionada y tardíamente a nuestros centros e institutos de investigación;

- La corrupción creciente y el narcotráfico destruyen el alma y el cuerpo de miles y miles de jóvenes y adultos en todos los rincones de las grandes ciudades y urbanizaciones de nuestra región y subregión latinoamericanas;

- Los cambios climáticos imprevisibles y las reservas de aguas decrecientes afectan la vida campesina, la agricultura y los campos y cultivos productivos;

- Los depredadores nacionales y transnacionales arrasan y contaminan el medio ambiente y los bosques nativos, comprometiendo así nuestro futuro.

La apretada síntesis de los hechos de la realidad, de la página anterior, nos lleva, justamente, a la dialéctica de que situaciones como las imperantes, demandan y requieren la estructuración de un esquema de seguridad subregional y vecinal viable, que contribuya a la calidad de vida de los pueblos de nuestros países, en un futuro que tienda a la paz, el desarrollo y la prosperidad, incrementando creadora e imaginativamente el actual esquema institucionalizado de integración multifacética del MERCOSUR, a través de nuevas ideas y propuestas, hacia el período 2000-2010, como actores comprometidos con una nueva agenda internacional, para ser implementada desde ahora y en el primer decenio del próximo siglo XXI.

Será una tarea prioritaria de la política exterior hilena y el MERCO$S U R$, ya que sin una subregión segura - único espacio ampliado que aborda un ámbito concreto y factible de aplicación - no tendremos capacidad política estatal ni responsabilidad internacional para seguir procurando y reclamando una región segura, como aporte a la seguridad global. ${ }^{62}$ Sin superación definitiva y solución pacífica completa de las controversias vecinales

${ }^{62} \mathrm{Al}$ respecto, véase en bibliografia, sección articulos: Jorge Vera Castillo, 1997. 
pendientes, algunas desde el siglo XIX, no podremos avanzar en el nuevo siglo en forma integrada y con continuidad.

Para adelantar efectivamente en la elaboración de una propuesta, debemos incorporar en la formulación y puesta en práctica de la Política exterior Chilena:

- en lo político-diplomático, la costumbre del principio de la buena vecindad;

- en lo político-estratégico, el ejercicio de las medidas de confianza mutuca;

- en lo conductual-cultural, el desarrollo de un nuevo enfoque y mentalidad;

- en lo conceptual-denominativo, la urgencia y el rigor de las nuevas ideas;

- en lo confidencial-inteligente, el trabajo con unas fientes y medios propios;

- en lo analítico-investigativo, el conocimiento prolijo de otros puntos de vista.

Un sendero para clarificaciones y precisiones, sugiero encontrarlo en expresiones del ex Ministro de Relaciones Exteriores de Chile, José Miguel Insulza, -que, en lo específico, sí comparto-, cuando ha escrito que: "Es claro que los intereses vitales de seguridad de nuestro país se ubican en América del Sur, y más específicamente en el Cono Sur. Pero tampoco Chile puede ignorar los problemas de seguridad que se registran más allá de nuestro entorno inmediato, no sólo en virtud de un deber de responsabilidad internacional, sino que también porque las cuestiones hemisféricas y regionales afectan igualmente nuestras opciones de seguridad." 63

En la línea de lo que venimos desarrollando y proponiendo, se inscribe la adopción - a sugerencia del Presidente de la República Argentina - de la muy relevante Declaración Política del MERCOSUR, Bolivia y Chile como Zona de Paz, durante la XIV Reunión del Consejo del Mercado Común, realizada en Ushuaia, el 24 de julio de 1998, (¡fecha del $215^{\circ}$ Natalicio de Simón Bolívar!).

Expresando una concreta y nítida voluntad política de sus Gobiernos, y guiados por principios, los Presidentes firmantes lo hicieron: "Convencidos de que la paz constituye el principal deseo de nuestros pueblos, conforma la base del desarrollo de la humanidad y representa la condición primordial para la existencia y continuidad del MERCOSUR" y también: "Convencidos de que un sistema de seguridad eficaz constituye un elemento esencial para el desarrollo de sus pueblos." Por tanto, resolvieron 10 puntos

63 Véase en bibliografia, secciôn libros: José Miguel Insulza. Ensayos sobre politica exterior de Chile, 1998, capittulo segundo, vi, pp. 102-115; p. 103. 
de acuerdo de la Declaración, de los cuales transcribo, ahora, los cuatro primeros y principales:

1.- Declarar al MERCOSUR, Bolivia y Chile como Zona de Paz y libre de armas de destrucción en masa.

2.- Manifestar que la paz constituye un elemento esencial para la continuidad y desarrollo del proceso de integración del MERCOSUR.

3.- Fortalecer los mecanismos de consulta y cooperación sobre temas de seguridad y defensa existentes entre sus miembros y promover su progresiva articulación, así como avanzar en la cooperación en el ámbito de las medidas de fomento de la confianza y la seguridad y promover su implementación.

4.- Apoyar en los foros internacionales pertinentes la plena vigencia y el perfeccionamiento de los instrumentos y mecanismos de no proliferación de armas nucleares y otras de destrucción en masa."

Y, en el último punto, dada su trascendencia político-estratégica, acordaron:

10.- Transmitir esta Declaración a los Secretarios Generales de la Organización de las Naciones Unidas y la Organización de los Estados Americanos y solicitarles su circulación como documento oficial de dichas organizaciones." 64

Desde una perspectiva de los intereses nacionales de Chile, nos parece fundamental la adopción de esta Declaración, y coherente con la ingente labor de abrir un camino hacia una seguridad subregional, con medidas de confianza mutua. En este mismo contexto, Chile debe desarrollar y privilegiar sus relaciones de cooperación en la esfera de seguridad y defensa con Argentina (en tanto principal país vecino, Estado parte del MERCOSUR y "Aliado Principal No Miembro de la OTAN" de los Estados Unidos) y con Brasil (en tanto principal país del MERCOSUR y con el cual hemos tenido y tenemos una amistad 'sin límites').

Además hay un aspecto primordial y complementario que no debe olvidarse. Nuestras relaciones bilaterales vecinales con el Perí no pueden ser excluidas de una concepción amplia, certera y responsable, en pos de que la propuesta que planteo sea posible. Relación que, como variable estratégica, es y será ineluctable.

64 Véase en bibliografía, sección documentos: Declaracion politica del Mercosur, Bolivia y Chile como zona de paz, 1998, pp. 25 y 26. 
Chile debe visualizar que una subregión segura, vecinal y viable, como la que postulamos, tiene que imaginar fórmulas, desde el presente hacia un futuro no lejano, que contemplen al Perú en sus acuerdos, configuración, diseño e implementación. Chile tiene una muy importante experiencia de relacionamiento con Perú, en la esfera que nos preocupa, la que se ha venido llevando a la práctica, en forma anual, ininterrumpida y regular, a través de las Rondas de Conversaciones entre los Altos Mandos de la Fuerzas Armadas de Chile y Perú, desde 1986. En 1999, la XIV Ronda de Conversaciones se desarrolla en Santiago.

Este proceso muy valioso, que amerita un estudio y seguimiento exacto, se fundaría en dos Comunicados Conjuntos de los Ministros de Relaciones Exteriores de Chile y Perú, emitidos después de decisivas reuniones de trabajo, la primera en Arica, Chile, del 7 al 9 de noviembre de 1985, y la segunda en Lima, el 28 y 29 de noviembre de 1985. En este último Comunicado Conjunto se acordó que: "10. En cumplimiento de lo acordado en la reunión de Arica, con respecto a encuentros de altos jefes de las Fuerzas Armadas para iniciar conversaciones destinadas a obtener una limitación de gastos en adquisiciones de armamentos, fomento de la confianza mutua y desarrollo de una concepción de seguridad que responda a una estrecha amistad y cfeciente cooperación entre ambas Naciones, los Ministros convinieron en que los mismos se celebren alternativamente en Chile y en el Perú. El primero de ellos se efectuará en Lima durante el mes de mayo próximo (1986), entre los Comandantes Generales y Comandantes en Jefe de las respectivas Fuerzas Armadas, asesoradas por sus Cancillerías." 65

El decurso ulterior de esta experiencia bilateral chileno-peruana ha sido bien registrada y valorada en el Libro de la Defensa Nacional de Chile, en particular, en el detalle de las Medidas de Confianza Mutua desarrolladas hasta ahora. ${ }^{66}$

\footnotetext{
65 Véase memoria del Ministerio de Relaciones Exteriores. República de Chile, correspondiente al año 1985, pp. 39-44; p. 44. Para un punto de vista peruano, véase Juan A. Velit Granda. “ Cooperación para la paz y medidas de confianza mutua: perspectiva del perú”, en Augusto Varas e Isaac Caro, op. cit., 1994, pp. 177-188. para un reciente y relevante punto de vista oficial chileno, véase en bibliografia, sección documentos: "Medidas de confianza mutua en la region: un imperativo para el próximo siglo", conferencia a cargo del Embajador Pablo Cabrera Gaete, en ese momento Subsecretario de Marina del Ministerio de Defensa Nacional de Chile, dictada en la Academia Diplomática del Perú, Lima, 1998, pp. 220-238.

to Vêase en bibliografía, sección libros: libro de la defensa nacional de Chile, 1997, p. 54 .
} 
Y privilegiar nuestras relaciones con Argentina y Brasil en el MERCO$S U R$, es conocer los puntos de vista, tanto de analistas gubernamentales como externos de estos dos países, en relación directa con el tema que nos ocupa. ${ }^{67} \mathrm{~A}$ partir del conocimiento de sus elaboraciones y planteamientos, podremos acceder a la fase de la credibilidad en la interlocución, como factores constitutivos básicos para la promoción de la seguridad a través de demostraciones de confianza mutua.

Marco político-estratégico bilateral de estas relaciones con Argentina es el Memorándum de Entendimiento para el Fortalecimiento de la Cooperación en Materia de Seguridad de Interés Mutuo, hecho en Santiago, el 8 de noviembre de 1995. Su seguimiento se hace con la agenda y tareas de las Reuniones del Comité Permanente de Seguridad Chileno-Argentino (COMPERSEG), cuya VI Reunión fue en Santiago, el 10 y 11 de diciembre de 1998. Esta : "Verificó la materialización de la voluntad expresada por los Ministros de Relaciones Exteriores y de Defensa en las reuniones de consulta, realizadas en Zapallar, Chile, en 1997, y en Campo de Mayo, Argentina, en 1998, para continuar avanzando en el proceso de cooperación bilateral en el ámbito de la seguridad y de la defensa y de fortalecimiento de la confianza entre ambos países." ${ }^{68}$ La tercera reunión de los Ministros será en Marbella, Chile, los días 10 y 11 de mayo de 1999.

\footnotetext{
67 Véanse, para conocer elaborados y previsores desarrollos al respecto, desde un punto de vista argentino y desde un punto de vista brasileño, respectivamente, en bibliografía, sección articulos: General (r) Antonino Fichera y mayor Carlos Daniel Esteban, 1994, pp. 215-222, y, general (Ejército del Brasil) Gleuber Vieira , 1994, pp. 12-19.

${ }^{6 B}$ Véase en bibliografía, sección documentos: acta de la vi reunion, 1998, 7 p; punto 3., p. 2. en esta misma acta, en su punto " 12 . reiteró la conveniencia de realizar un seminario sobre "seguridad y defensa en el mercosur y países asociados" en dos fases, una a realizarse en santiago durante el primer semestre de 1999 y la otra en buenos aires, el segundo semestre del mismo año." en el caso de la realización de la primera fase del referido seminario, êsta se llevará a efecto en los primeros días del mes de julio próximo de 1999. además, sobre los vinculos especificos bilaterales chileno-argentinos en el ámbito de las $\mathrm{mcm}$, puede consultarse el texto íntegro de la exposicion conjunta argentina - chile medidas de confianza mutua, efectuada por el embajador pablo cabrera gaete, subsecretario de marina de chile, en la tercera conferencia de ministros de defensa de las américas, cartagena de indias colombia, $1^{\circ}$ de diciembre de $1998,8 \mathrm{p}$.
} 


\section{Sugerencias de política para un nuevo gobierno}

Las sugerencias que planteo se enmarcan en el contexto de nuestra principal idea-fuerza de sintesis acerca de la política exterior chilena hacia el período 2000-2010, que debiera guiar las elaboraciones, formulaciones y puestas en práctica de un nuevo Gobierno, desde el 11 de marzo del próximo año 2000.

Postulo una Política exterior Chilena que tiene identidad e intereses nacionales, para preservarlos y desarrollarlos; con relaciones bilaterales de buena vecindad; con integración multifacética y regionalismo abierto; que se inserta en un mundo cada vez más cercano, informado e interconectado, y, en el actual cambio de periodo histórico que se ha incubado en la última década del siglo XX y se seguirá expresando y erigiendo plenamente desde la primera década del siglo XXI.

Al esbozar nuestro planteamiento, hemos debido tomar en cuenta que Chile: "es un país pequeño de sólo 14 millones de habitantes y con una capacidad de mercado limitada que se refleja en un PIB de aproximadamente US\$ 64.000 millones". A la vez, "El MERCOSUR representa una población 14 veces más grande y un PIB 12 veces el de Chile (200,5 millones. de habitantes y US $\$ 730$ mil millones.), esto significa que los 4 países del MERCOSUR reúnen el $44 \%$ de la población de América Latina y el $54 \%$ del PIB correspondiente", y que, lo que no es irrelevante estratégicamente, "el MERCOSUR sólo representa el 3,6\% de la población mundial y sólo el 2,6\% del PIB mundiales.", como lo consigna y recuerda acertadamente un analista miembro del Ejército de Chile. ${ }^{69}$

Además, y a pesar de los cambios y del nuevo ambiente subregional, aún se estima necesario: "preguntarse si los proyectos políticos de desarrollo y de inserción internacional de cada uno de los países del MERCOSUR son de tipo complementario, competitivo o excluyente, y hasta donde está dispuesto a llegar cada uno de ellos en su modificación para compatibilizarlos. Este es un aspecto crucial a dilucidar para avanzar en el estudio de la problemática de la seguridad nacional y regional de los miembros del MERCOSUR"; de acuerdo con el punto de vista de otro analista miembro de las

69 Véase en bibliografia, sección articulos: Manuel Concha M., 1996, p. 63 . 
Fuerzas Armadas, específicamente de la Armada de Chile. ${ }^{70}$

Estas sugerencias son las siguientes, en el marco del Tema que nos ocupa:

1a.- La política exterior chilena deberá establecer y tener muy claras sus prioridades para el periodo 2000-2010; comunicarlas oportunamente a los medios de comunicación social y difundirlas pedagógicamente a la opinión pública, al comienzo del nuevo gobierno, y reiterarlas periódicamente, sin ambigüiedades.

2a.- Dentro de estas prioridades deberán privilegiarse las relaciones bilaterales de buena vecindad de Chile con Argentina, Bolivia y Perú, en todos los planos y esferas potenciales, de beneficio mutuo. Con Bolivia se requiere un nuevo enfoque.

3a.- En consecuencia, las relaciones de Chile -en tanto actual pais asociado y como eventual país miembro en un futuro de mediano plazo - con el MERCOSUR y'sus Estados partes y otros países asociados, deberá ser una de las principales prioridades del conjunto de la Política exterior Chilena.

4a.- Estas relaciones con el MERCOSUR y sus estados partes y otros países asociados se extenderán más allá de los "aspectos exclusivamente comerciales y económicos ", para expresarse concretamente en la esfera de la concertación, consulta y diálogo políticos democráticos, a través de la cooperación política.

5a.- En coherencia con lo anterior, las relaciones de Chile con el MERCOSUR deberán explorar y concretar su diversificación y expansión hacia la materialización de una cooperación de nuevo tipo en la esfera de la seguridad y defensa.

6a.- La experiencia de las relaciones bilaterales chileno-argentinas, en la esfera de la seguridady' defensa, deberán ser conocidas y consideradas adecuada y primordialmente para otros emprendimientos con los otros estados partes del MERCOSUR, en el respectivo plano bilateral, y en el ámbito subregional viable.

7a.- Chile deberá tener iniciativa y continuar lo ya avanzado en materia de reconceptualización de la seguridad regional y subregional, para lo cual deberá preparar propuestas para ser expuestas y discutidas en la Cuarta 
Conferencia de Ministros de Defensa de las Américas, a realizarse en Brasil durante el año 2000, en conjunto con los Estados partes y países asociados del MERCOSUR.

8a.- Chile deberá continuar con la implementación, puesta en práctica y seguimiento de Medidas de Confianza Mutua, en sus relaciones con el MERCOSUR, sus Estados partes y países asociados, teniendo presente que éstas son de distinto carácter y alcances. ${ }^{71}$

I .- de carácter político.

II .- de carácter diplomático.

III.- de carácter educativo y cultural.

IV.- de carácter militar:

a).- relacionadas con movimientos de tropas y Ejércitos;

b).- relativas al intercambio de información;

c).- relacionadas con el intercambio de personal;

d).- relacionadas con las comunicaciones;

e).- relacionadas con contactos;

f).- relacionadas con entrenamiento y educación.

9a.- Chile deberá constituir, actualizar y seguir desarrollando un Registro de Expertos sobre Medidas de Fomento de la Confianza y de la Seguridad, en acuerdo con la Resolución AG/RES: 1566 (XXVIII-O/98) de la OEA, referida a Fomento de la Confianza y de la Seguridad en las Américas, en su Punto 11.

10a.- Chile deberá dar un muy importante salto cualitativo en lo relativo a información y análisis de inteligencia, como parte de su hacer políticodiplomático y político-estratégico, para lo cual deberá destinar, dentro de las estructuras de sus Ministerios de Relaciones Exteriores y de Defensa, los recursos humanos y materiales necesarios para esta ingente e ineludible tarea nacional, como Política de Estado. Un Servicio de Inteligencia Estatal, también en su rama de Servicios Exteriores, es necesario aún en tiempos de paz y cooperación, y deberá vencer equivocados prejuicios, que sólo producirán faltas de información inexcusables. ${ }^{72}$ 
11a.- La faceta de los equilibrios estratégicos, como un prerequisito de una subregión segura, por una parte, y por otra, la existencia del caso de un país que establece una alianza extra regional -como lo es la condición de Argentina, con su status de Aliado Principal No Miembro de la OTAN/Major Non-NATO Ally (MNNA), de los Estados Unidos, formalmente desde el sábado 31 de enero de 1998-, es un desafío y problemática no menor, que Chile debe poner, franca y no tardíamente, en el debate bilateral, vecinal, subregional y regional. Por cierto, no se trata de algo 'simbólico'. ${ }^{73}$

12a.-La Política exterior Chilena deberá tener en cuenta, simultáneamente, en la esfera de la seguridad y defensa , que: $1^{\circ}$ ) en el siglo XXI se observarán nuevos roles de las Fuerzas Armadas, sin abandonar su rol básico de defensa de la soberanía nacional, incluso en nuestra subregión y en el MERCOSUR ${ }^{74}$; $2^{\circ}$ ) existen y subsistirán diferentes percepciones sobre seguridad y defensa en América Latina, y sobre las consecuentes amenazas, riesgos y oportu-nidades; $\left.3^{\circ}\right)$ los procesos de integración económica y física y' de concertación y consulta política van a ir teniendo mayores influencias en la seguridad y defensa, $\mathrm{y}, 4^{\circ}$ ) el camino de la cooperación militar, en sus tres niveles diferentes pero interrelacionados (político, militar-estratégico e intercambio entre los servicios), demanda nuevas mentalidades distintivas, en las diferentes ramas de las Fuerzas Armadasy sus Altos Mandos, bajo la guía de la práctica de medidas de confianza mutua, de distinto carácter, en sus relaciones bilaterales vecinales y subregionales.

13a.- Por su parte, el Ministerio de Defensa Nacional de Chile requiere importantes cambios en su estructura, funciones y tareas, ante nuevas reali-

\footnotetext{
72 Vêase en bibliografia: sección articulos: Jorge Vera Castillo, rev. 1, 1998, p. 3. ahî hago referencia a una cita, que previene que: "no puede haber una verdadera independencia, ninguna soberanía real a menos que uno posea un servicio de inteligencia confiable. la inteligencia de afuera, aun cuando provenga de los mejores amigos, nunca es 100 por ciento confiable. la experiencia ha confirmado esto en numerosas veces.". esta se encuentra en una entrevista concedida al editor internacional del semanario alemán Focus, Hans Peter Oschwald, por parte del presidente de francia, Jacques Chirac, para el Global Viewpoint, en Paris: Vẻase en El Mercurio, Santiago de Chile, sábado 27 de septiembre de 1997, p. d7. un ejemplo aleccionador del sentido concreto de las prevenciones que planteamos, se encuentra en la falta de información anticipatoria y sustantiva del gobierno de chile en la temática del otorgamiento del status de "aliado principal no miembro de la otan", por parte de los estados unidos a la República Argentina, a petición de ésta. este episodio debe ser estudiado muy rigurosamente por las autoridades del nuevo gobierno chileno, ya sea por fuentes abiertas o por fuentes de inteligencia, propiamente tales, para evitar su repetición y obtener su esclarecimiento. 33 Véase en bibliografía, sección articulos, páginas 47 y 48 . ahi se encuentran varias referencias sobre esta delicada materia, como análisis y artículos, editoriales e informaciones, tanto de fuentes abiertas chilenas como argentinas.
}

74 Vêase en bibliografia, secciön monografias: Wendy Hunter, 1996, 49 p. 
dades. $1^{\circ}$ ) Actualmente, es el único Ministerio de no tiene una subrogancia clara y habitual en ausencia del Ministro, y cuenta con cinco Subsecretarios. $\left.2^{\circ}\right)$ Su 'Comité de Coordinación y Seguimiento de Materias Internacionales' de Defensa' debiera ser sustituido, y organizarse bajo el cargo y mando de un Viceministro de Asuntos Político-Estratégicos Internacionales. $\left.3^{\circ}\right) \mathrm{La}$ Subsecretaría de Guerra debe ser una Subsecretaría de Ejército (¿o de Paz?), así como existen las Subsecretarías de Marina y de Aviación. $4^{\circ}$ ) Igualmente el $M D N$ deberá acotar, elaborar y fijar directrices, sobre la presencia pública y rol de los Departamentos Comunicacionales de las distintas ramas de las Fuerzas Armadas, reglamentándolos en forma muy disciplinada y estricta en su aplicación, bajo la efectiva práctica de una política democrática de las instituciones armadas, en su sujeción al poder civil. $5^{\circ}$ ) El $M D N$ debe ser un centro articulador y generador de nuevas relaciones civiles - militares, con una mirada de futuro. ${ }^{75}$

14a.- Por último, el Gobierno de Chile debe tener y tomar iniciativas en el ámbito subregional y del MERCOSUR, en la esfera de la seguridad y defensa, a través de propuestas concretas, que tiendan a institucionalizar, interestatal e intergubernamentalmente, la cooperación y el intercambio en esta esfera. Para avanzar, propongo tres iniciativas de institucionalización, a partir del próximo año 2000 :

- Primera. Reuniones anuales de los Ministros de Defensa de los Estados partes y Países Asociados del MERCOSUR: estableciéndose el Consejo de Ministros de Defensa del MERCOSUR.

- Segunda. Rondas de Conversaciones regulares (con una periodicidad a concordar) entre los Altos Mandos de las Fuerzas Armadas de los Estados partes y Países Asociados del MERCOSUR: hacia la configuración de un Estado Mayor de Altos Mandos de las FF.AA. del MERCOSUR.

- Tercera. Encuentros de Comités Binacionales y/o Cuatripartitos Permanentes de Seguridad, instituidos en estos últimos años, por los Estados partes y Países Asociados del MERCOSUR: de modo de posibilitar la creación de un Comite Permanente de Seguridad del MERCOSUR.

75 Para obtener un punto de vista muy orientador sobre las futuras relaciones civiles-militares en Chile, veáse en bibliografía, secciớn monografias: Andrés Zaldivar Larrain, 1998, 31 p. 


\section{Promoviendo la seguridad, demostrando confianza}

Así Chile podrá ayudar en la edificación de una seguridad subregional con medidas de confianza mutua, como prioridad de su Política exterior, en la especificidad de sus relaciones con el MERCOSUR. Con esta opción político-estratégica, la política exterior chilena contribuirá, en los hechos concretos, a la seguridad regional de América Latina, en su calidad de Estado Miembro de la Organización de los Estados Americanos, y, por ende, y coherente con su deber de responsabilidad internacional, colaborará fielmente al mantenimiento de la paz,y la seguridad global, como Miembro de la Organización de las Naciones Unidas. ${ }^{76}$

En la perspectiva de alcanzar y desarrollar un esquema de seguridad subregional vecinal y viable, será fundamental que, junto al principio de la buena vecindad, vayamos intentando transformar en un nuevo principio de nuestra política exterior y' de Defensa, la voluntad política que se exprese a través una conducta gubernamental, institucional y humana que tienda a estar promoviendo la seguridad, demostrando confianza.

Lo anterior deberá ser asimilado adecuada y preferentemente por quienes estarán a cargo de la toma de decisiones, en diversas coyunturas internacionales, regionales, subregionales, vecinales y bilaterales; tanto de potencial conflicto como de real cooperación, de acuerdos y de discrepancias, de avances y de retrocesos.

Y particularmente, la utilización de las atractivas y recurrentes expresiones, ya sea de "interés nacional" o de "seguridad nacional", por parte de miembros de las Fuerzas Armadas o por parte de 'dirigentes políticos nacionalistas', deberá ser escrutada cuidadosamente en cada ocasión, más aún cuando se utilicen en función de explicar y fundamentar dichos y/o

\footnotetext{
${ }^{76}$ La participación de las Fuerzas Armadas de Chile y del Mercosur en las Operaciones de mantenimiento de la paz de la ONU - componente fundamental en la diplomacia preventiva - debe ser estimulada. para este propósito superior integracionista en la esfera de la seguridad y defensa, el centro argentino de entrenamiento conjunto para operaciones de paz (caecopaz), inaugurado por el presidente menem el 27 de junio de 1995, puede y debe cumplir un rol singular. complementariamente, al respecto, véase en bibliografía, secciôn monografias: general de división Carlos María Zabala, 1997, 15 p. en el caso de una de las ramas de las FF.AA. chilenas, véanse puntos de vista institucionales, en: "participación del Ejército de Chile en operaciones de mantenimiento de la paz" (artículo preparado pui la dirección de operación del ejército); "participación de las telecomunicaciones en misiones de paz (a nivel internacional)" (articulo preparado por el r.t. $n^{a} 9$ "soberania"), y, tcl. (oss) Juan E. Parra Z. "participación del servicio de sanidad en las misiones de paz a nivel internacional", a \& 5 - armas \& servicios, Ejército de Chile, $n^{\circ} 61$, 1995, pp. 8-20.
} 
actuaciones que vayan en sentido contrario del que venimos postulando; ya que él, eventualmente, corresponderá efectiva y programáticamente con sus propios matices, por cierto- a la política exterior chilena para el período $2000-2010 .{ }^{77}$

De allí que responsabilidad esencial del Presidente de la República, en Chile, en tanto poseedor de las atribuciones especiales que le entrega la Constitución Política de la República, dentro del Artículo 32, en lo que se refiere a:

10. " Designar a los embajadores y ministros diplomáticos, y a los representantes ante organismos internacionales.", y que "estos funcionarios ... serán de la confianza exclusiva del Presidente de la República y se mantendrán en sus puestos mientras cuenten con ella;"

17.- " Conducir las relaciones políticas con las potencias extranjeras y organismos internacionales, y llevar a cabo las negociaciones; concluir, firmar y ratificar los tratados que estime convenientes para los intereses del país," y,

19. " Disponer de las fuerzas de aire, mar y tierra, organizarlas y distribuirlas de acuerdo con las necesidades de la seguridad nacional", resultan de particular relevancia y significación política para la elaboración, formulación y puesta en práctica de la política exterior y de defensa, en el próximo Gobierno. ${ }^{78}$ Mas, las prerrogativas presidenciales no debieran excluir su debate.

Otro aspecto que pasa a ser fundamental en el decurso ulterior de nuestras relaciones bilaterales vecinales es la percepción que de ellas tenga la opinión pública nacional, en sus muy diversos componentes - sean ellos más o menos especializados, ilustrados o ajenos en el tema que nos ha ocupado -, la que se informa, forma y deforma a través de los distintos medios de comunicación social.

Una información oficial oportuna, sensata y veraz será siempre un elemento determinante, en un sentido u otro, para que la opinión pública obtenga y tenga una vinculación fundada e interesada con los contenidos de la política exterior y la inserción internacional de Chile. De allíse derivarán y se implementarán, racionalmente, las emociones y' sentimientos patrióticos que se van generando en cada ciudadano y cada pueblo. Por tanto, la desinformación y la manipulación engañosa deben ser desechadas y eliminadas totalmente, como even-

\footnotetext{
77 Véase en bibliografia, secciôn libros: John A. Vasquez, 1994, iii. Politica exterior y conflicto mundial, en unidad 6: "explicaciones sobre política exterior", pp. 167-178.

${ }^{8}$ Véase constitucion politica de la republica de chile, edíción actualizada, editorial siena, 1996, en capitulo iv, pp. 29-31.
} 
tual práctica o recurso de difusión de nuestras política exterior y política de defensa.

En este plano, no serían aceptables abusos deliberados ante la opinión pública y los medios de comunicación social (sus comentaristas, editores y reporteros 'especializados' temporal o prolongadamente), a partir del conocimiento y expertizaje propios de esta esfera de la política gubemamental, en sus conceptos, contenidos, datos e informaciones específicos, que intentaran realizarse desde los Ministerios de Relaciones Exteriores y de Defensa Nacional, ya sea a alto nivel o de parte de funcionarios intermedios. Además, las filtraciones y los trascendidos noticiosos no deben ser autorizados y/o estimulados, ya que se constituyen en elementos muy nocivos de los ambientes y de las mentalidades, en particular, en cuanto a nuestras relaciones exteriores bilaterales vecinales. ${ }^{79}$

La propuesta que hemos elaborado requiere -junto con lo ya puntualizado anteriormente en la Sección V., en sus páginas 26 y 27 - de la mayor transparencia informativa ${ }^{80}$ que sólo podría aceptar y considerar restricciones muy puntuales, frente a coyunturas muy singulares de nuestras relaciones exteriores. En efecto, una opinión pública informada no debe ser temida y sí debe ser contemplada como un elemento constitutivo de nuestro poder nacional como Estado y como sociedad, lo cual debe ser una preocupación inherente de nuestra Política exterior Chilena.

En suma, las relaciones de Chile con el MERCOSUR propenderán a promover la seguridad subregional, con demostraciones de confianza mutua, como una contribución cardinal para el avance, consolidación y enfoque de su proceso de integración, tendiente a la creación de una comunidad de valores democráticos y humanistas, coadyuvando al desarrollo socioeconómico y bienestar de sus países.

${ }^{79} \mathrm{Al}$ respecto, importantes y pertinentes desarrollos sobre los vínculos entre medios de comunicaciôn social y política exterior, véase en bibliografía, sección libros: Simón Serfaty (compilador), 1995, en particular, segunda parte. pp. 137-209, y, tercera parte, pp. 211-268.

8o Un ejemplo notable, pero escaso, de lo que sostengo, está representado por la publicación del libro de la defensa nacional de chile, en agosto de 1997. su difusión debiera ampliarse a colegios, escuelas, universidades e instituciones diversas interesadas, a través de ediciones masivas, de buena calidad pero de bajo costo, o con una distribución estatal gratuita. 
$\underline{\operatorname{Anexo} N^{\circ} 1}$

Cronología basica de la vinculación de Chile con el MERCOSUR*

(Agosto 1994 - Diciembre 1998)

Hecho / Situación: Presencia del Presidente Eduardo Frei Ruiz-Tagle, como invitado especial. Ocasión: VI Reunión Consejo Mercado Común.

Lugar: Buenos Aires, Argentina.

Fecha: 05/08/94.

Hecho / Situación: Declaración de los Presidentes del MERCOSUR y de la República de Chile, relativa a la participación de Chile como observador en grupos de trabajo a ser acordados con los países del Mercosur.

Ocasión: VI Reunión Consejo Mercado Común.

Lugar: Buenos Aires, Argentina.

Fecha: 05/08/94.

Hecho / Situación: Asistencia del Ministro de Economía de Chile, como invitado especial.

Ocasión: VII Reunión Consejo Mercado Común.

Lugar: Ouro Preto, Brasil.

Fecha: 17/12/94.

Hecho / Situación: Presencia del Presidente Eduardo Frei Ruiz-Tagle, como invitado especial. Ocasión: VIII Reunión Consejo Mercado Común.

Lugar: Asunción, Paraguay .

Fecha: 04 y 05/08/95.

Hecho / Situación: Presencia del Ministro de Relaciones Exteriores de Chile.

Ocasión: IX Reunión Consejo Mercado Común.

Lugar: Punta Del Este, Uruguay.

Fecha: 06 y 07/12/95.

Hecho / Situación: Presencia del Presidente de Chile, Eduardo Frei Ruiz-Tagle.

Ocasión: X Reunión Consejo Mercado Común.

Lugar: San Luis, Argentina.

Fecha: 25/06/96.

Hecho / Situación: Suscripción del Acuerdo de complementación económica Chile-MERCOSUR. Ocasión: X Reunión Consejo Mercado Común.

Lugar: San Luis, Argentina.

Fecha: 25/06/96.

Hecho / Situación: Protocolo de adhesión a la "Declaración sobre compromiso democrático en el MERCOSUR".

Ocasión: X Reunión Consejo Mercado Común.

Lugar: San Luis, Argentina.

Fecha: 25/06/96.

* Investigaciōn y elaboración del autor - (Scl. 25/01 - 02/03/1999) -; Quien agradece la muy valiosa colaboración, a travês de diversas fuentes documentales, del Señor Jorge Torrealba Pacheco, Ministro Consejero, de la Di. rección de América del Sur, del Ministerio de Relaciones Exteriores de Chile. 
Hecho / Situación: Declaración de los Presidentes de los Estados partes del MERCOSUR, la República de Bolivia y de la Repüblica de Chile "sobre Malvinas".

Ocasión: X Reunión Consejo Mercado Común.

Lugar: San Luis, Argentina.

Fecha: 25/06/96.

Hecho / Situación: Presencia del Presidente Eduardo Frei Ruiz-Tagle, como invitado especial. Ocasión: XI Reunión Consejo Mercado Común.

Lugar: Fortaleza, Brasil.

Fecha: 17/12/96.

Hecho/ Situación: Decisión $N^{\circ}$ 14/96 sobre participación de terceros países asociados en reuniones del MERCOSUR.

Ocasión: XI Reunión Consejo Mercado Común.

Lugar: Fortaleza, Brasil.

Fecha: 17/12/96.

Hecho / Situación: Acuerdo sobre servicios aéreos subregionales entre Argentina, Bolivia, Brasil, Chile, Paraguay y Uruguay.

Ocasión: Xi Reunión Consejo Mercado Común.

Lugar: Fortaleza, Brasil.

Fecha: 17/12/96.

Hecho / Situación: Participación Presidente Eduardo Frei Ruiz-Tagle.

Ocasión: XII Reunión Consejo Mercado Común.

Lugar: Asunción, Paraguay.

Fecha: 19/06/97.

Hecho / Situación: Resolución sobre la participación de Chile en el mecanismo de consulta y concertación política.

Ocasión: XII Reunión Consejo Mercado Común.

Lugar: Asunción, Paraguay.

Fecha: 19/06/97.

Hecho / Situación: Decisión N ${ }^{\circ}$ 12/97 sobre participación de Chile en reuniones del MERCOSUR.. Ocasión: XIII Reunión Consejo Mercado Común.

Lugar: Montevideo, Uruguay .

Fecha: 15/12/97.

Hecho / Situación: Entendimiento relativo al plan de cooperación y asistencia reciproca para la seguridad regional en el MERCOSUR, la República de Bolivia y la República de Chile, y anexo ad hoc.

Ocasión: Reunión de Ministros de Relaciones Exteriores.

Lugar: Buenos Aires, Argentina.

Fecha: 23/07/98.

Hecho / Situación: Entendimiento entre el Mercosur, la República de Bolivia y la República de Chile relativo al mecanismo conjunto de registro de compradores y vendedores de armas de fuego, municiones, explosivos y otros Materiales relacionados.

Ocasión: Reunión de Ministros de Relaciones Exteriores.

Lugar: Buenos Aires, Argentina.

Fecha: 23/07/98. 
Hecho / Situación: Participación Presidente Eduardo Frei Ruiz-Tagle.

Ocasión: XIV Reunión Consejo Mercado Común.

Lugar: Ushuaia, Argentina.

Fecha: 24/07/98.

Hecho / Situación: Declaración política del MERCOSUR, Bolivia y Chile como Zona de Paz. Ocasión: XIV Reunión Consejo Mercado Común.

Lugar: Ushuaia, Argentina.

Fecha: $24 / 07 / 98$.

Hecho / Situación: Protocolo de Ushuaia sobre compromiso democrático en el MERCOSUR, la República de Bolivia y la República de Chile.

Ocasión: XIV Reunión Consejo Mercado Común.

Lugar: Ushuaia, Argentina.

Fecha: 24/07/98.

Hecho / Situación: Participación Presidente Eduardo Frei Ruiz-Tagle.

Ocasión: XV Reunión Consejo Mercado Común.

Lugar: Río de Janeiro, Brasil.

Fecha: 10/12/98.

Hecho / Situación: Proclamación de Río De Janeiro hecha por los Presidentes de los países del MERCOSUR y países asociados en conmemoracion de los 50 años de la Declaración Universal de los Derechos Humanos.

Ocasión: XV Reunión Consejo Mercado Común.

Lugar: Río de Janeiro, Brasil.

Fecha: 10/12/98.

Hecho / Situación: Acuerdo sobre extradición entre los Estados partes del MERCOSUR

y la República de Bolivia y la República de Chile.

Ocasión: XV Reunión Consejo Mercado Común.

Lugar: Río de Janeiro, Brasil.

Fecha: 10/12/98. 


\section{Anexo $N^{\circ} 2$}

Medidas de fomento de la confianza y de la seguridad que se acordó recomendar en las conferencias regionales ad-hoc de Santiago y de San Salvador.

\section{(Noviembre de 1995 y Febrero de 1998)}

1.- Gradual adopción de acuerdos sobre notificación previa de ejercicios militares;*

2.- Intercambio de información y participación de todos los Estados miembros en el Registro de Armas Convencionales de las Naciones Unidas y en el Informe Estandarizado sobre gastos militares;

3.- Fomento de la elaboración y el intercambio de información sobre políticas y doctrinas de defensa.

4.- Consideración de un proceso de consultas con miras a avanzar en la limitación y control de armas convencionales;

5.- Acuerdos sobre invitación de observadores para ejercicios militares, visitas a instalaciones militares, facilidades para observar operaciones rutinarias e intercambio de personal civil y militar para formación, capacitación y perfeccionamiento;

6.- Reuniones y acciones para prevenir incidentes e incrementar la seguridad en el tránsito terrestre, marítimo y aéreo;

7.- Programas de cooperación en casos de desastres naturales o para prevenir tales desastres, sobre la base de la petición y autorización de los Estados afectados;

8.- Desarrollo e implementación de las comunicaciones entre las autoridades civiles o militares de países vecinos de conformidad con su situación fronteriza;

9.- Realización de seminarios, cursos de difusión y estudios sobre medidas de fomento de la confianza mutua y de la seguridad, y políticas de fomento de la confianza con participación de civiles y militares, así como sobre las preocupaciones especiales de seguridad de los pequeños Estados insulares;

10.- Realización de una reunión de alto nivel sobre las preocupaciones especiales de seguridad de los pequeños Estados insulares;

\section{1.- Programas para la paz;}

12.- Estimular contactos y cooperación entre legisladores sobre medidas de fomento de la confianza y temas relacionados con la paz y la seguridad hemisférica, incluyendo la realización de encuentros, intercambio de visitas y una reunión de parlamentarios, a fin de fortalecer este proceso; **

* Estas primeras 11 Medidas fueron explicitadas en la DECLARACION DE SANTIAGO, suscrita al têrmino de la Conferencia Regional sobre Medidas de Fomento de la Confianza y de la Seguridad, realizada en Santiago de Chile, del 8 al 10 de Noviembre de 1995.

** Estas últimas 9 Medidas fueron explicitadas en la DECLARACION DE SAN SALVADOR, suscrita al tërmino de la Conferencia de San Salvador sobre Medidas de Fomento de la Confianza y de la Seguridad en Seguimiento de la Conferencia de Santiago, realizada en San Salvador, El Salvador, del 25 al 27 de Febrero de 1998. 
13.- Extender a los institutos de formación diplomática, academias militares, centros de investigación, y universidades, los seminarios, cursos y estudios contemplados en las Declaraciones de Santiago y de San Salvador, sobre medidas de fomento de la confianza y de la seguridad, desarme y otros temas vinculados a la paz y la seguridad hemisférica, con participación de funcionarios gubernamentales, civiles y militares, así como de la sociedad civil, en dichas actividades;

14.- Identificar y desarrollar actividades que promuevan la cooperación entre países vecinos en sus zonas fronterizas;

15.- Promover el intercambio de información, entre otros, a través de la publicación de libros de defensa o documentos oficiales, según sea el caso, que permita una mayor transparencia en materia de políticas de defensa de cada país, así como sobre la organización, estructura, tamaño y composición de las fuerzas armadas;

16.- Con el propósito de promover la transparencia y con el apoyo técnico de organismos internacionales económicos apropiados, estimular la realización de estudios tendientes a avanzar en el establecimiento de una metodología común que facilite la comparación del gasto militar en la región, teniendo en cuenta, entre otros, el Informe Estandarizado Internacional sobre Gastos Militares de las Naciones Unidas;

17.- Desarrollar un programa de cooperación para atender las preocupaciones presentadas por el transporte marítimo de desechos nucleares y otros desechos, así como cooperar y coordinar en los foros internacionales pertinentes para el fortalecimiento de las normas que regulan este transporte y su seguridad;

18.- Continuar apoyando los esfuerzos de los pequeños Estados insulares para atender sus preocupaciones especiales de seguridad, incluyendo aquellas de naturaleza económica, financiera y del medio ambiente, tomando en consideración su vulnerabilidad y nivel de desarrollo;

19.- Mejorar y ampliar la información que los Estados miembros remiten al Registro de Armas Convencionales de la ONU, a fin de fortalecer la contribución del Hemisferio a los objetivos de dicho registro, en cumplimiento de las resoluciones pertinentes de la Asamblea General de la ONU, $y$,

20.- Continuar con las consultas e intercambio de ideas dentro del Hemisferio para avanzar en la limitación y el control de armas convencionales en la región. 
Bibliografía:

Jorge Vera Castillo

Política exterior chilena y

MERCOSUR.

\section{Artículos}

"Aliado principal", El Mercurio, (editorial), Santiago de Chile, Jueves 14 de Agosto de 1997, p. a3.

"Aliado principal: Más allá del simbolismo". Seis países gozan de la calidad de "socio extra otan" de Estados Unidos", El Mercurio, Santiago de Chile, Domingo 17 de agosto de 1997, p. a4.

"Argentina, aliado principal de EE.UU.", La Segunda, (editorial), Santiago de Chile, Martes 12 de Agosto de 1997, p. 6.

"Argentina da carácter "disuasivo" a sus FF.AA. presupuesto de reequipamiento no podrá gastarse en armas ofensivas", El Mercurio, Santiago de Chile, Domingo 22 de marzo de 1998, p. a5.

"Argentina se adapta a nueva realidad estratégica. al proponer el fin de la hipótesis de conflicto con Chile", El Mercurio, Santiago de Chile, Lunes 13 de julio de 1998, p. a5.

"Brasil prepara creación de Ministerio de Defensa. la nueva repartición debiera entrar en funcionamiento el próximo año", El Mercurio, Santiago de Chile, Viernes 6 de marzo de 1998, p. a7.

Cabrera, Pablo. "La seguridad como factor de integración". Convergencia trasandina, Revista Oficial de la Embajada de Chile en Argentina, año 2, número 7, Buenos Aires, Septiembre 1998, pp. 9 y 10.

Caro, Isaac. "Medidas de confianza mutua en Sudamérica", Estudios Internacionales, año XXVIII, $N^{\circ} 109$, Instituto de Estudios Internacionales, Universidad de Chile, Enero-Marzo 1995, pp. 37-57.
Carvallo, Mauricio. "Chile y las amenazas del siglo XXI. Cancillería y' defensa se unen para enfrentarlas", EI Mercurio, (reportaje), Santiago de Chile, Domingo 22 de Octubre de 1995, pp. d14 y d15.

Carvallo, Mauricio. "La fiesta de los abrazos. Punta Arenas se hizo estrecho", El Mercurio, (reportaje), Santiago de Chile, Domingo 21 de febrero de 1999, pp. d2-d5.

Concha Martinez, Brigadier General (r) Manuel. "Visión político-estratégica del MERCOSUR", Politica y Estratégia, $N^{\circ} 69$, Academia Nacional de Estudios Políticos y Estratégicos (Anepe), Santiago de Chile, Mayo-Agosto 1996, pp. 60-68.

"FFAA. argentinas instan a defensa común. plantean tema de seguridad en el cono sur a partir de integración", El Mercurio, Santiago de Chile, Miércoles 3 de junio de 1998, p. c4.

Fichera, General (r) Antonino, y Esteban, Mayor Carios Daniel. "Criterios rectores para fonnulación de medidas de confianza en un ámbito de seguridad cooperativa para el cono sur", en Augusto Varas e Isaac Caro. editores. Medidas de confianza mutua en America Latina, Flacso-Stimson Center-Ser, FLACSO, Santiago de Chile, 1994, pp. 215-222.

Gomarix, Enrique. "Las medidas de confianza mutua en la Europa de fin de siglo", en Augusto Varas e Isaac Caro, editores. Medidas de confianza mutua en América Latina, Flacso-Stimson Center-Ser, FLACSO, Santiago de Chile, 1994, pp. 31-41.

"Insisten con una alianza extra-nato", La Nación, Buenos Aires, Argentina, Sábado 26 de abril de 1997, p. 8.

"La Argentina, aliada extra-nato", La Nación, (editorial), Buenos Aires, Argentina, Miércoles 4 de febrero de 1998, p. 12.

"Menem en los Estados Unidos", La Nación, (editorial), Buenos Aires, Argentina, Lunes 9 de diciembre de 1996, p. 6. 
Milet, Paz. "El diálogo regional sobre medidas de confianza mutua", Fuerzas Armadas y Sociedad (Fasoc), año 11, $N^{\circ} 1$, Facultad Latinoamericana de Ciencias Sociales (Flacso), sede Chile, Enero-Marzo 1996, pp. 11-15.

"Militares chilenos y argentinos preparan los futuros ejercicios", La Nación (line), Buenos Aires, Argentina, Lunes 22 de Febrero de 1999, 2 p.

"Millonaria modernización de FFAA. brasileñas. invertirä cuatro mil millones de dólares en programas de rearme", El Mercurio, Santiago de Chile, Martes 12 de mayo de 1998, p. a6.

"Perfilan doctrina de seguridad en MERCOSUR. polémica por documento extraoficial", El Mercurio, Santiago de Chile, Miércoles 30 de julio de 1997, p. a5.

Pericás Neto, Bernardo. "Perspectivas do sistema interamericano", en Gélson Fonseca Júnior e Sergio Henrique Nabuco de Castro (organizadores), temas de política externa brasileira II, volume I, Instituto de Pesquisa de Relações Internacionais, Río de Janeiro, 1994, pp. 123-134.

"Potencias Regionales", El Mercurio, (editorial), Santiago de Chile,

Sábado 23 de agosto de 1997, p. a3.

“¿Qué pasó con la seguridad hemisférica? a 50 años del Tiar", El Mercurio, Santiago de Chile, Sábado 1 de Noviembre de 1997, p. d8.

Rojas s., Patricio. "Balance del sector defensa 1990-1994", Fuerzas Armadas y Sociedad (Fasoc), año 9, vol. IX, No 1 , Facultad Latinoamericana de Ciencias Sociales (Flacso), sede Chile, Enero-Marzo 1994, pp. 43-50.

"Se formalizó ayer la alianza extra-nato con EE.UU.", La Nación, Buenos Aires, Argentina, Domingo $1^{\circ}$ de febrero de 1998 , pp. 1 y 6 .
Thauby g., Capitán de Navío (r) Fernando. "El Mercosur y la seguridad del subcontinente", Fuerzas Armadas y Sociedad, año $12, \mathrm{~N}^{\circ} 1$, Facultad Latinoamericana de Ciencias Sociales (Flacso), sede Chile, Enero-Marzo 1997, pp. 16-26.

Vera Castillo, Jorge. "OTAN y no proliferacion nuclear. Una mirada desde Chile". Notas para comisión internacional PDC, Santiago, 18 de Abril de 1997, 3 p.

Vieira, General (Ejército, Brasil) Gleuber. "La variable estratégica en el proceso de constitución del mercosur", Fuerzas Armadas y sociedad (Fasoc), año 9, vol. IX, $N^{\circ} 2$, Facultad Latinoamericana de Ciencias Sociales (Flacso), sede Chile, Abril-Junio 1994, pp. 12-19.

\section{Documentos}

Acta de la VI reunión del comité permanente de seguridad chilenoargentino. hecha en Santiago de Chile, el 11 de Diciembre de 1998, 7 p.

Acta final de la conferencia sobre la seguridad $y$ la cooperacion en Europa. Helsinki, $1^{\circ}$ de Agosto de 1975: en Thomas Buergenthal, editor. Derechos Humanos, derecho internacional y el acuerdo de Helsinki, (edición en español), Ediciones Centenario, Montevideo, Uruguay, 1979, apendice, pp. 227-278.

Acuerdo de complementacion economica Chile - MERCOSUR. suscrito en la provincia de San Luis, República Argentina, el 25 de Junio de 1996: en Diplomacia, $N^{\circ} 69$, Academia Diplomática de Chile, Santiago, Marzo-Junio 1996, pp. 88-99.

Acuerdo de cooperacion para el afianzamiento de la paz y la amistad entre las FF.AA. de las repúblicas de Bolivia, Chile y Perú. Santiago de Chile, 27 de mayo de 1976: en Hugo Palma V. El sistema internacional en sus textos, tomo II, Centro Peruano de Estudios Internacionales (Cepei), Lima, Perú, 1990, pp. 1209-1212. 
Bases programáticas del segundo gobierno de la Concertación. Un gobierno para los nuevos tiempos. "Septimo compromiso: una politica exterior para los nuevos tiempos", Santiago de Chile, 1993, pp. 124-132.

"Compromiso de Santiago con la democracia $y$ la renovacion del sistema interamericano" (aprobado en Ia tercera sesión plenaria celebrada el 4 de junio de 1991): en actas y documentos volúmen I, Organización de los Estados Américanos, Asamblea General, vigésimo primer período ordinario de sesiones, Santiago, Chile, del 3 al 8 de Junio de 1991, oea/ser.p/xxi. o.2, 20 de agosto 1991, volumen I, pp.1-3.

Compromiso de Acapulco para la paz, el desarrollo y la democracia. (Declaracion de los Jefes de Estado del Grupo de los Ocho). Acapulco, México, 27 de Noviembre de 1987: en Hugo Palma V. El sistema internacional en sus textos, tomo I, Centro Peruano de Estudios Internacionales (Cepei), Lima, Perú, 1990, pp. 308-320.

Comunicado conjunto de los Presidentes de los Estados partes del MIERCOSUR, Bolivia y Chile. XIV Reunión del Consejo del Mercado Común. Ushuaia, República Argentina, 24 de julio de 1998, 3 p.

Comunicado de la I reunión del Consejo del Mercado Común del Sur, Brasilia, 17 de Diciembre de 1991: en Integración Latinoaméricana, año $17, N^{\circ} 175$, intal, Buenos Aires, Enero-Febrero 1992, pp. 64 y 65 .

Comunicados conjuntos de los Presidentes (1991-1997): en Boletîn Oficial del MERCOSUR, año I, $\mathrm{N}^{\circ} 3 / 97$, Diciembre 1997, Montevideo, pp. 74-119.

Conferencia de prensa del Canciller don Jose Miguel Inzulsa, Ministerio de Relaciones Exteriores, Santiago de Chile, Miếrcoles 23 de Diciembre de 1996, 17 p.
"Consideration of guidelines for confidence-building measures". Res. 39/63 e: en The United Nations General Assembly and Disarmament 1984, United Nations, New York, 1985, pp. 23-26.

Declaración conjunta de los Presidentes de la República de Chile y de la República Argentina. Auscrita en Buenos Aires, Argentina, el 15 de Diciembre de 1998, 7 p.

Declaración de Ayacucho. Lima, 9 de Diciembre de 1974: en Hugo Palma V. El sistema internacional en sus textos, tomo I, Centro Peruano de Estudios Internacionales (Cepei), Lima, perú, 1990, pp. 289-293.

Declaración de Cartagena. Tercera Conferencia de Ministros de Defensa de las Américas, Cartagena de Indias, República de Colombia, 2 de Diciembre de 1998, 4 p.

Declaración de Ica. (Declaracion de los Jefes de Estado del Grupo de los Ocho). Ica, Perú, 12 de Octubre de 1989: en Hugo Palma V. El sistema internacional en sus textos, tomo I, Centro Peruano de Estudios Internacionales (Cepei), Lima, 1990, pp. 329-340.

Declaración de Panamá.

Declaracion de la XII Cumbre de Jefes de Estado y de Gobierno del Grupo de Rio, 4-5 de Septiembre de 1998, 12 p.

Declaración de San Carlos de Bariloche. Segunda Conferencia de Ministros de Defensa de las Américas, San Carlos de Bariloche, República Argentina, 9 de Octubre de 1996, 2 p.

Declaración de San Salvador sobre medidas de fomento de la confianza y' de la seguridad (Adoptada en la Quinta sesión plenaria, celebrada el 28 de Febrero de 1998). Conferencia regional de San Salvador sobre medidas de fomento de la confianza y de la seguridad en seguimiento de la conferencia de Santiago, 25 al 27 de Febrero de 1998, San Salvador, El Salvador, y, anexo: Organización de los Estados Américanos, oea/ser.k/xxix.2, cosegre. ii/doc.7/98 rev.2, 28 febrero 1998, 8 p. 
Declaración de Santiago. II Cumbre de las Américas, y, Plan de Acción II Cumbre de las Américas. Santiago de Chile, 18 de Abril de 1998, 6 p., y, 34 p.

Declaración de Santiago sobre medidas de fomento de la confianza y de la seguridad. Santiago de Chile, 10 de Noviembre de 1995: en fuerzas armadas y sociedad (Fasoc), año 10 , vol. X, $N^{\circ} 4$, Facultad

Latinoamericana de Ciencias Sociales (Flacso), sede Chile, Octubre-Diciembre 1995, pp. 58-60.

Declaración de Uruguay. (Declaracion de los Jefes de estado del Grupo de los Ocho). Punta del Este, Unuguay, 29 de octubre de 1988: en Hugo Palma V. El sistema internacional en sus textos, tomo I, Centro Peruano de Estudios Internacionales (Cepei), Lima, 1990, pp. 321-329.

\section{Declaración politica del MERCOSUR,} Bolivia y Chile como zona de paz. Hecha en Ushuaia, República Argentina, el 24 de Julio de 1998: en fuerzas armadas y sociedad (Fasoc), año 13, $\mathrm{N}^{\circ} 3$,

Facultad Latinaoméricana de Ciencias Sociales (Flacso), sede Chile, Julio-Septiembre 1998, pp. 25 y 26.

Declaración presidencial antártica chileno-argentina. Suscrita en Ushuaia, República Argentina, el 16 de febrero de 1999, 2 p.

Declaración presidencial conjunta chilenoargentina sobre fomento de la confianza $y$ seguridad. Suscrita en Ushuaia, República Argentina, el 16 de febrero de 1999, 2 p.

Declaración presidencial sobre dialogo politico entre los estados partes del MERCOSUR. Potrero de los Funes, provincia de San Luis, República Argentina, 25 de Junio de 1996, 2 p.

Declaraciôn presidencial sobre la consulta $y$ concertacion politica de los estados partes del MERCOSUR. Asunción, República del Paraguay, 17 Junio 1997, 1 p.
Déclaration adoptée a la conférence des Ministres des Affaires Étrangères des états membres du traité de Varsovie. Prague, le 31 Octobre 1969: en Les Nouvelles de Moscou, $N^{\circ} 45$, Moscou, 8 Novembre 1969, p. 6.

Diálogo Unión Europea - Grupo de Río sobre medidas de fomento de la confianza mutua. Documento de base preparado para el seminario "Diálogo Unión europea Grupo de Río sobre medidas de fomento de la confianza mutua", Punta del Este, Uruguay, 9-11 de octubre de 1995, Instituto de Relaciones Europeo-Latinoaméricanas (Irela), Madrid, 1995, 42 p.

Discurso del Señor Ministro de Relaciones Exteriores, don Jose Miguel Insulza, en la inauguración de la II Jornada Internacional de Defensa y Seguridad Regional en el Cono Sur, Santiago, 3 de Noviembre de 1997, 8 p.

Discurso del Señor Ministro de Relaciones Exteriores, don Jose Miguel Insulza, en la Conferencia Regional sobre medidas de Fomento de la Confianza y de la Seguridad.

Santiago, 8 de Noviembre de 1995: en Fuerzas Armadas y Sociedad (Fasoc), año 10 , vol. $X, N^{\circ} 4$, Facultad Latinoamericana de Ciencias Sociales (Flacso), sede Chile, Octubre-Diciembre 1995, pp. 47-50.

Documents de la conférence de Bucarest du comité politique consultatif des états signataires du traité de Varsovie sur l'amitié, la cooperation et l'entraide, du 4 au 6 Juillet 1966: en Les Nouvelles de Moscou, supplément au numéro 29, Moscou, 16 Juillet 1966, pp. 2-18.

Exposición conjunta argentina - chile medidas de confianza mútua (Embajador Pablo Cabrera Gaete, Subsecretario de Marina de Chile), Tercera Conferencia de Ministros de defensa de las Américas, Cartagena de Indias - Colombia, $1^{\circ}$ de diciembre de $1998,8 \mathrm{p}$. 
Guzman Correa, José Florencio. Clase magistral del señor Ministro de Defensa Nacional, en la inauguracion del año académico de las Fuerzas Armadas, edificio Diego Portales, Santiago de Chile, Miércoles 17 de marzo de 1999, 11 p.

"Medidas de confianza mutua en la región: Un imperativo para el próximo siglo". Conferencia a cargo del Embajador Pablo Cabrera Gaete, Subsecretario de Marina del Ministerio de Defensa Nacional de Chile, dictada en la Academia Diplomática del Perú, Lima, 26 de Noviembre de 1998, en: Politica Internacional, $\mathrm{N}^{\circ} 54$, Revista de la Academia Diplomática del Perú, Lima, Octubre/Diciembre 1998, pp. 220-238.

Palma v., Hugo. Medidas de confianza reciproca. Comisión sudamericana de paz, documento de trabajo, Seminario internacional "Seguridad democrática regional: Un concepción alternativa de seguridad", Santiago de Chile, 23 al 26 de marzo de 1988, Santiago de Chile, 1988, 63 p.

Participação de terceiros países associados em reuniões do MERCOSUL. mercosul/cmc/dec. $n^{\circ} 14 / 96$,

XI cmc - Fortaleza, 17/12/96, 2 p.

Participación de Chile en reuniones del MERCOSUR. mercosur/cmc/dec. $\mathrm{n}^{\circ} 12 / 97$, XIII cmc - Montevideo, 15/xii/97, 3 p.

Perez Yoma, Edmundo. Clase magistral en Anepe, discurso pronunciado por el ministro de Defensa Nacional de Chile en la Academia Nacional de Estudios Políticos y Estratégicos (Anepe), Santiago, 12 de mayo de 1994: en fuerzas armadas y sociedad (Fasoc), Año 9, $N^{\circ}$ 2, Facultad Latinoamericana de Ciencias Sociales (Flacso), sede Chile, abril-junio 1994, pp. 28-34.

Perez Yoma, Edmundo. Defensa nacional: resultados y desafios, Conferencia del Ministro de Defensa Nacional de Chile en la apertura del año académico de las Academias de Guerra y Politécnicas de las Fuerzas Armadas, Santiago, 18 de Marzo de 1997: en fuerzas armadas y sociedad (fasoc), año 12 , $\mathrm{N}^{\circ}$ 1, Facultad Latinoamericana de Ciencias Sociales (Flacso), sede Chile, Enero-Marzo 1997, pp. 48-57.

Perez Yoma, Edmundo. La defensa nacional en el umbral del siglo XXI, Presentación del Ministro de Defensa Nacional de Chile en la Cámara Chileno-Norteamericana (Amcham Chile), Santiago, 9 de septiembre de 1997: en fuerzas armadas y sociedad (Fasoc), año 12, $\mathrm{N}^{\circ} 4$, Facultad Latinoamericana de Ciencias Sociales (Flacso), sede Chile, Octubre-Diciembre 1997, pp. 26-31.

Política de defesa nacional.

Presidência da República, Governo

Fernando Henrique Cardoso, Secretaría de Comunicação Social, Brasília, 1996, 11 p.

\section{Presentación del Ministro de Defensa} Nacional, don Edmundo Perez Yoma, en la "II Jornada sobre Defensa y Seguridad Regional en el Cono Sur".

Santiago, 4 de Noviembre de 1997, 13 p.

\section{Protocolo de Ouro Preto.}

Protocolo adicional al tratado de Asunción sobre la estructura institucional del MERCOSUR, Ouro Preto, Brasil, 17 de Diciembre de 1994: en Integración Latinoaméricana, año 19, $\mathrm{N}^{\circ} 206$, Intal, Buenos Aires, Diciembre 1994, pp. 66-71.

Protocolo de Ushuaia sobre compromiso democrático en el MERCOSUR, la República de Bolivia y la República de Chile. hecho en Ushuaia, República Argentina, el 24 de Julio de 1998, 4 p.

Resolución ag/res. 1566 (xxviii-o/98)

"Fomento de la confianza y de la seguridad en las Américas" (Resolución aprobada en la Tercera sesión plenaria, celebrada el 2 de Junio de 1998): en actas y documentos volúmen I, Organización de los Estados Américanos, asamblea general, Vigésimo Octavo período ordinario de sesiones, Caracas, Venezuela, del 1 al 3 de junio de 1998, oea/ser.p/XXVWI-O.

2, 28 Octubre 1998, volumen 1, pp. 75-78. 
Resolución ag/res. 1570 (XXVIII-O/98)

"Cooperación para la seguridad hemisferica" (Resolución aprobada en la tercera sesión plenaria, celebrada el 2 de Junio de 1998): en actas y documentos volúmen I, Organización de los Estados Américanos, asamblea general, Vigésimo Octavo período ordinario de sesiones, Caracas, Venezuela, del 1 al 3 de junio de 1998, oea/ser.p/XXVIII-O.2, 28 Octubre 1998, volumen 1, pp. 88 y 89 .

\section{Resolución ag/res. 1604 (XXVIII-O/98)}

"Programa de educacion para la paz en el hemisferio" (Resolución aprobada en la Quinta sesión plenaria, celebrada el 3 de Junio de 1998): en actas y documentos volúmen I, Organización de los Estados Américanos, asamblea general, Vigésimo octavo período ordinario de sesiones, Caracas, Venezuela, del 1 al 3 de junio de 1998, OEA/SER.P/XXVIII-O.2,

28 octubre 1998, volumen 1, pp. 154 y 155 .

Resolución ag/res. 1494 (XXVII-O/97) "Medidas de fomento de la confianza y de la seguridad en las américas" (Resolución aprobada en la Séptima sesión plenaria, celebrada el 5 de Junio de 1997): en actas y documentos volumen $i$, organización de los Estados Américanos, asamblea general, vigésimo séptimo período ordinario de sesiones, Lima, Perú, del 1 al 5 de junio de 1997, OEA/SER.P/XXVII-O.2, 3 de Noviembre 1997, volúmen 1, pp. 115-117.

\section{Resolución ag/res. 1409 (XXVI-O/96)}

"Medidas de fomento de la confianza y la seguridad en las Américas" (Resolución aprobada en la Octava sesión plenaria, celebrada el 7 de Junio de 1996): Actas y documentos volumen I, Organización de los Estados A méricanos, asamblea general, Vigésimo sexto período ordinario de sesiones, Panamá, República de Panamá, del 3 al 7 de junio de 1996, OEA/SER.P/XXVI-O.2, 25 Septiembre 1996, volúmen 1, pp. 111-114.

Resoluciones ag/res. 1284 (xxiv-o/94)

"Informacion sobre gastos militares y registro de armas convencionales" (Resolución aprobada en la décima sesión plenaria, celebrada el 10 de junio de 1994); ag/res. 1285 (XXIV-O/94) "Junta

Interamericana de Defensa" (Resolución aprobada en la Décima sesión plenaria, celebrada el 10 de junio de 1994); ag/res. 1288 (XXIV-O/94) "Medidas para el fortalecimiento de la confianza y la seguridad en la región": en actas y documentos volumen I, organización de los Estados Americanos, asamblea general, Vigésimo cuarto período ordinario de sesiones, Belém do Pará, Brasil, del 6 al 10 de junio de 1994, OEA/SER.P/XXIV.O.2, 23 de Septiembre 1994 , volúmen 1 , pp. 130 y 131, pp. $132 \mathrm{y}$ 133, y, pp. 138-140.

Resolución ag/res. 1237 (XXII-O/93) "Reunion de expertos sobre medidas de fomento de la confianza y mecanismos de seguridad en la región" (Resolución aprobada en la Novena sesión plenaria, celebrada el 11 de junio de 1993): en actas y documentos volumen $i$, organizacion de los Estados Americanos, asamblea general, Vigésimo Tercer periodo ordinario de sesiones, Managua, Nicaragua, del 7 al 11 de Junio de 1993, oea/ser.p/xxiii.o.2, 30 de Septiembre 1993, Volúmen 1, pp. 115 y 116.

\section{Resolución ag/res. 1179 (XXII-O/92)}

"Cooperación para la seguridad y el desarrollo hemisfericos. Contribuciones regionales a la seguridad global" (Resolución aprobada en la octava sesión plenaria, celebrada el 23 de mayo de 1992): en actas y documentos volúmen $\mathrm{I}$, Organización de los Estados Américanos, asamblea general, Vigésimo Segundo período ordinario de sesiones, Nassau, Las Bahamas, del 18 al 23 de Mayo de 1992, OEA/SER.P/XXII.O.2, 21 Junio 1992, volúmen 1, pp. 100-105.

Resolución ag/res. 1121 (XXI-O/91) "Cooperación para la seguridad en el hemisferio. Limitación de la proliferación de los instrumentos de guerra y armas de destrucción masiva" (Resolución aprobada en la Undécima Sesión plenaria, celebrada el 8 de Junio de 1991): en actas y documentos Volúmen I, organización de los Estados Americanos, asamblea general, Vigésimo Primer periodo ordinario de sesiones, Santiago, Chile, del 3 al 8 de Junio de 1991, 
OEA/SER.P/XXI.O.2, 20 agosto 1991, volúmen I, pp. 107 y 108.

\section{Resolución ag/res. 1123 (XXI-O/91) \\ "Cooperación para la seguridad hemisferica" (Resolución aprobada en la Undécima sesión plenaria, celebrada el 8 de Junio de 1991): en actas y documentos volúmen I, organización de los Estados Américanos, asamblea general, Vigésimo Primer período ordinario de sesiones, Santiago, Chile, del 3 al 8 de Junio de I991, OEA/SER.P/XXI.O.2, 20 Agosto 1991, volúmen I, pp. 117 y 118. \\ Resolución cp/res. 650 (1031/95) "Junta interamericana de defensa": en acla de la sesión extraordinaria celebrada el I de junio de 1995. Aprobada en la sesión del 2 de febrero de 1996, Organización de los Estados Americanos, consejo permanente, OEA. SER.G, CP/ACTA. 1031/95, 1 Junio 1995, anexo, p.25.}

Resolution adopted on the report of the ad hoc committee of the tenth special session. S-10/2. Final document of the Tenth Special Session of the general assembly: en resolutions and decisions adopted by the general assembly during its tenth special session, 23 may - 30 june 1978, United Nations, New York, 1978, pp. 3-15.

Seguridad regional: panorama y perspectivas. Ponencia del Dr. Patricio Rojas Saavedra, presidente cees, en II jornada de defensa y seguridad regional en el cono sur, corporación de estudios estratégicos (cees), Santiago, 4 Noviembre 1997, 18 p.

Tratádo para la Constitucion de un mercado común entre la República Argentina, la República Federativa del Brasil, la República del Paraguay' y la Republica Oriental del Uruguay. Tratado de Asuncion. Suscrito en Asunción, República del Paraguay, el 26 de marzo de 1991: en Integración Latinoaméricana, año $16, N^{\circ} 167$, Intal, Buenos Aires, Mayo 1991, pp. 111-113, $\mathrm{y}$, anéxos, pp. 113-117.
Tratado interamericano de asistencia reciproca. Suscrito en Río de Janeiro el 2 de septiembre de 1947 en la Conferencia Interamericana para el Mantenimiento de la Paz y la Seguridad del Continente: en serie sobre tratados 25 , oea/ser.x/4 rev. 1, Organización de los Estados Américanos, secretaria general, Washington, d.c., 1972, pp. 49-59.

\section{Libros}

El MERCOSUR de la Defensa: Estudio estratégico de América Latina y' el Caribe 1996, FLACSO - Cladde - P\&SA , Flacso, Santiago de Chile, 1997, 225 p.

Gardner, Gary. No proliferación núclear: Un mamıal, (Edición original en inglés de 1994), Icla - Revista Occidental, México, 1994, 191 p.

Insulza, José Miguel, Ensayos sobre politica exterior de Chile, Editorial Los Andes, Santiago de Chile, 1998, 191 p.

Libro de la defensa nacional de Chile. Editor responsable: Ministerio de Defensa Nacional de Chile, Santiago, Agosto 1997, $224 \mathrm{p}$.

Medidas de fomento de la confianza y de la seguridad en las Américas: Libro de consulta de documentos hemisfericos, U.S. arms control and disarmament agency, (Edición bilingüe inglés/español), Washington, D.C., Septiembre 1998, 418 p.

Serfaty, Simón. (Compilador). Medios de comunicacion masivos y politica exterior, (Edición original en inglés de 1991 by foreign policy institute), Ediciones Devenir, Buenos Aires, 1995, 378 p.

Varas, Augusto y Caro, Isaac, Editores. Medidas de confianza mutua en América Latina, Flacso-Stimson Center-Ser, FLACSO, Santiago de Chile, 1994, 222 p. 
Vasque» a., John. (Editor compilador). Relaciones internacionales. El pensamiento de los clásicos, (edición original en inglés de 1990, second edition, by prentice-hall, inc.), Editorial Limusa-Noriega editores, México, 1994, $420 \mathrm{p}$.

\section{Monografías}

Hunter, Wendy. State and soldier in Latin America.. redefining the military's role in Argentina, Brazil, and Chile, Peaceworks $N^{\circ} .10$, United States Institute of Peace, Washington, DC., October 1996, 49 p.

Zabala, General de División Carlos María. Asunto: Exposición la experiencia argentina en misiones de paz, con anexo 1, Ministerio de Defensa, Estado Mayor conjunto de las Fuerzas Armadas, Buenos Aires, República Argentina, 1997, 15 p.

Zaldivar Larrain, Andrés. El congreso y la defensa nacional. una mirada de futuro. Conferencia dictada por el Senador, Sr. Andrés zaldivar Larraín, Presidente deI Senado, en la Academia de Guerra Naval, Valparaíso, Viernes 2 de octubre de 1998, 31 p.

\section{Noticiarios}

"Ejercicio combinado de armadas de Chile y" Argentina": en Revista de Marina, año CXIV volúmen 115, número 846, $\left(N^{\circ} 5 / 98\right)$, Valparaíso, Chile,

Septiembre - Octubre 1998, p. 507.

"Nuevos ejercicios combinados con armada Argentina": en Revista de Marina, año CXIV volúmen 115 , número 847 , (No 6/98), Valparaíso, Chile, Noviembre - Diciembre 1998, p. 608. 